\title{
Monitoring of Protein Biomarkers of Inflammation in Human Traumatic Brain Injury Using Microdialysis and Proximity Extension Assay Technology in Neurointensive Care
}

\author{
Philip Dyhrfort,, ${ }^{1, *}$ Qujin Shen,, ${ }^{2, *}$ Fredrik Clausen,, Måns Thulin,, ${ }^{3,4}$ Per Enblad,, Masood Kamali-Moghaddam, ${ }^{2}$ \\ Anders Lewén, ${ }^{1, *}$ and Lars Hillered ${ }^{1, *}$
}

\begin{abstract}
Traumatic brain injury (TBI) is followed by secondary injury mechanisms strongly involving neuroinflammation. To monitor the complex inflammatory cascade in human TBI, we used cerebral microdialysis (MD) and multiplex proximity extension assay (PEA) technology and simultaneously measured levels of 92 protein biomarkers of inflammation in MD samples every three hours for five days in 10 patients with severe TBI under neurointensive care. One $\mu \mathrm{L}$ MD samples were incubated with paired oligonucleotide-conjugated antibodies binding to each protein, allowing quantification by real-time quantitative polymerase chain reaction. Sixty-nine proteins were suitable for statistical analysis. We found five different patterns with either early (<48 h; e.g., CCL20, IL6, LIF, CCL3), mid (48-96 h; e.g., CCL19, CXCL5, CXCL10, MMP1), late (>96 h; e.g., CD40, MCP2, MCP3), biphasic peaks (e.g., CXCL1, CXCL5, IL8) or stable (e.g., CCL4, DNER, VEGFA)/low trends. High protein levels were observed for e.g., CXCL1, CXCL10, MCP1, MCP2, IL8, while e.g., CCL28 and MCP4 were detected at low levels. Several proteins (CCL8, -19, -20, -23, CXCL1, -5, -6, -9, -11, CST5, DNER, Flt3L, and SIRT2) have not been studied previously in human TBI. Cross-correlation analysis revealed that LIF and CXCL5 may play a central role in the inflammatory cascade. This study provides a unique data set with individual temporal trends for potential inflammatory biomarkers in patients with TBI. We conclude that the combination of MD and PEA is a powerful tool to map the complex inflammatory cascade in the injured human brain. The technique offers new possibilities of protein profiling of complex secondary injury pathways.
\end{abstract}

Keywords: biomarkers; inflammation; microdialysis; molecular tools; neurointensive care; proteomics; traumatic brain injury

\section{Introduction}

$\mathbf{T}$ RAUMATIC BRAIN INJURY (TBI) is a complex and heterogeneous disorder depending on multiple variable factors, such as initial mechanical forces, comorbidities, age, coagulopathy, time to neurosurgical intervention, and others. The primary injury makes the brain susceptible for additional secondary molecular, chemical, and pathophysiological adverse events that may continue for a considerable time. ${ }^{1}$ Among such secondary injury mechanisms, neuroinflammation is thought to be of special importance. ${ }^{2} \mathrm{Neu}-$ roinflammation after trauma involves activation of the peripheral and innate immune systems by complicated triggering and maintainance mechanisms through numerous pathways including cy- tokines, chemokines, growth factors, receptor activation, and others. ${ }^{3}$ Improved possibilities for monitoring neuroinflammation within the brain after TBI are needed greatly.

The development of cerebral microdialysis (MD) catheters with larger cutoff membranes offers possibilities for protein sampling, ${ }^{4-6}$ especially in combination with new molecular analysis tools such as the deoxyribonucleic acid (DNA) assisted proximity ligation assay (PLA) technique. ${ }^{7}$ The PLA was introduced as a tool for ultrasensitive measurements of proteins in liquid samples in which each protein is recognized by two different oligonucleotide-conjugated antibodies followed by an enzymatic ligation step and quantitative real-time polymerase chain reaction (qPCR) amplification.

\footnotetext{
${ }^{1}$ Department of Neuroscience, Section of Neurosurgery, ${ }^{2}$ Department of Immunology, Genetics and Pathology, Science for Life Laboratory, ${ }^{3}$ Department of Statistics Uppsala University, Uppsala, Sweden.

${ }^{4}$ School of Mathematics and Maxwell Institute for Mathematical Sciences, University of Edinburgh, Edinburgh, United Kingdom.

*These authors contributed equally to the article.

(c) Philip Dyhrfort et al., 2019; Published by Mary Ann Liebert, Inc. This Open Access article is distributed under the terms of the Creative Commons Attribution Noncommercial License (http://creativecommons.org/licenses/by-nc/4.0/) which permits any noncommercial use, distribution, and reproduction in any medium, provided the original author(s) and the source are credited.
} 
The second generation of this technique, known as proximity extension assay (PEA), ${ }^{8,9}$ allows extremely specific and sensitive simultaneous detection of up to 92 proteins and four internal controls in just $1 \mu \mathrm{l}$ sample volume. The combination of protein sampling with MD followed by sensitive multiplex protein detection may be useful clinically for temporal mapping of complex secondary injury events such as neuroinflammation in patients with TBI in the neurointensive care (NIC) setting. ${ }^{10}$

We present a feasibility study on 10 patients with severe TBI by analyzing 92 potential protein biomarkers of inflammation using PEA technology on $3 \mathrm{~h}$ MD fractions over the first five days after admission to the Uppsala NIC unit.

\section{Methods}

All research procedures described here were approved by the Regional Ethical Review Board at Uppsala University, and informed consent was obtained from the closest relatives of the patients.

\section{Patient population and neurocritical care management}

The Department of Neurosurgery at the University Hospital in Uppsala, Sweden, provides neurosurgical care for those in the central part of Sweden; the population is approximately two million persons. Most patients are treated initially at local hospitals according to advanced trauma life support (ATLS) principles and then referred to Uppsala (the most distant local hospital is $382 \mathrm{~km}$ away).

For this study we conveniently recruited 10 patients ( 9 male, 1 female) with severe TBI, defined as a post-resuscitation Glasgow Coma Scale (GCS) score of 8 or below on admission to our NIC unit, with a history of cranial trauma, and a computed tomography (CT) scan consistent with TBI. All patients required NIC treatment including intubation, mechanical ventilation, and monitoring of intracranial pressure (ICP) and MD. The patients were treated according to a standardized brain injury protocol aiming to keep ICP below $20 \mathrm{~mm} \mathrm{Hg}$ and cerebral perfusion pressure (CPP) above $60 \mathrm{~mm} \mathrm{Hg} .{ }^{11}$

In brief, patients were sedated using continuous intravenous propofol infusion $(1-4 \mathrm{mg} / \mathrm{kg} / \mathrm{h}$ Propofol-Lipuro; B. Braun Melsungen AG, Melsungen, Germany) combined with intermittent intravenous morphine (1-3 mg Morfin Media; Media, Sollentuna, Sweden). Normovolemic circulation and sufficient colloid osmotic pressure were aimed for. Infusion of $20 \%$ albumin was used commonly to manage hypovolemia/hypotension. Fever was managed with paracetamol, cooling blanket, or chlorpromazine. Lesions (contusions and extracerebral hematomas) with significant mass effect were evacuated.

In situations of increased ICP despite basic NIC treatment and when no mass lesion was present, cerebrospinal fluid (CSF) was drained. If CSF drainage was not sufficient to reduce ICP, a thiopental infusion was started. Finally, if ICP was still refractory, a decompressive craniectomy was performed. Inotropic agents (dobutamine or norepinephrine) were administered when needed. Plasma glucose was measured frequently and maintained at 5$10 \mathrm{mmol} / \mathrm{L}$. Additional injuries were scored according to the New Injury Severity Score (NISS), ranging from 1 to $75 .^{12}$

At approximately six months post-injury, patient outcome was assessed using the extended Glasgow Outcome Scale (GOSE). ${ }^{13}$ Patient gender, age, mechanism of injury, presence of coagulopathy, GCS motor score on admission and discharge, length of stay in the NIC unit, MD start time (h after injury), and GOSE are presented in Table 1.

\section{Radiological analysis and neurosurgical interventions}

The CT scans were performed frequently as needed. The placement of the MD catheter in relation to the injury was recorded. The Rotterdam CT score $^{14}$ was used for TBI classification in addition to a crude sorting of the patients according to the most dominant cerebral injury visible on CT (Table 2). In cases where several types of injuries were equally present (e.g., traumatic subarachnoid hemorrhage, contusions, subdural hematomas), the term "mixed" brain injury was used.

The basal cisterns and the midline shift were measured and calculated on the last CT scan before the surgical procedure. Compression of the basal cisterns was determined by the following scoring system: $0=$ normal, $1=$ compressed yet visible, $2=$ compressed. The midline shift was calculated at the level of the thalami (Table 2). Table 2 also lists data on neurosurgical monitoring and interventions.

\section{Microdialysis procedure}

The MD procedure has been described previously in detail. ${ }^{15}$ Briefly, the MD catheter was inserted in conjunction with implantation of the ICP monitoring device in the nondominant frontal lobe, $1-2 \mathrm{~cm}$ anterior to the coronal suture. The 71 High Cut-Off (100 kDa) Brain MD catheter was used with a membrane length of $10 \mathrm{~mm}$ (M Dialysis AB, Stockholm, Sweden). Artificial CSF was used as perfusion fluid, containing $\mathrm{NaCl} 147 \mathrm{mM}, \mathrm{KCl} 2.7 \mathrm{mM}$, $\mathrm{CaCl}_{2} 1.2 \mathrm{mM}$, and $\mathrm{MgCl}_{2} 0.85 \mathrm{mM}$ with the addition of $1.5 \%$ human serum albumin, at a perfusion rate of $0.3 \mu \mathrm{L} / \mathrm{min}$ delivered by a 106 Microdialysis pump (M Dialysis).

Sampling was started at least $2 \mathrm{~h}$ after insertion of the MD catheter to allow for normalization of changes caused by catheter implantation. The MD vials were changed on an hourly basis according to our routine MD protocol. Samples $(\sim 18 \mu \mathrm{L})$ were analyzed at the bedside using an ISCUSflex Microdialysis Analyzer (M Dialysis) for routine low molecular weight biomarkers of energy metabolism (glucose, lactate, pyruvate) and cellular distress (glutamate and glycerol). The Lactate/Pyruvate Ratio (LPR) was calculated. Urea was monitored to control the MD catheter performance. ${ }^{16}$ The remaining samples $(\sim 10 \mu \mathrm{L})$ were stored at $-70^{\circ} \mathrm{C}$ until protein biomarker analysis.

The ISCUSflex Microdialysis Analyzer was automatically calibrated when started, as well as every $6 \mathrm{~h}$ using standard calibration solutions from the manufacturer (M Dialysis). Quality controls at two different concentrations for each substance were performed every weekday. Total imprecision coefficient of variation was $<10 \%$ for all analytes.

The following cutoff values for the MD routine biomarkers were considered critical based on published data ${ }^{17-19}$ : glucose $<0.8 \mathrm{mmol} / \mathrm{L}$; lactate $>4 \mathrm{mmol} / \mathrm{L}$; pyruvate $<120 \mu \mathrm{mol} / \mathrm{L} ; \mathrm{LPR}>25$; glutamate $>15 \mu \mathrm{mol} / \mathrm{L}$; glycerol $>100 \mu \mathrm{mol} / \mathrm{L}$. The MD biomarker concentrations were not corrected for in vivo relative recovery, which is expected to be close to $70 \% .^{20}$

\section{Protein biomarker analysis}

Levels of 92 potential protein biomarkers in brain MD samples were measured simultaneously by multiplex PEA (Olink ${ }^{\circledR}$ Inflammation panel, Olink Proteomics AB, Uppsala, Sweden) as described previously. ${ }^{21}$ In brief, $1 \mu \mathrm{L}$ of liquid sample was incubated with a set of paired antibodies where two oligonucleotideconjugated antibodies binds to the same protein. The affinity bindings of the antibodies bring the two attached oligonucleotides in proximity, allowing them to be extended using enzymatic DNA polymerization. The resulting double-strand DNAs were subsequently amplified and quantified by real-time qPCR by microfluidic PCR system (Fluidigm, San Francisco, CA).

The raw $\mathrm{Ct}$ values were normalized against negative- and spiked-in controls to achieve relative quantification values as NPX (Normalized Protein eXpression). This a unit in $\log 2$ scale, which is correlated positively with the protein concentration. An increase of 1 NPX represents a two-fold increase of protein concentration in the sample. Each protein has its own value of 
Table 1. Proteins in the 92-Plex Proximity Extension Assay Inflammation Panel

\begin{tabular}{|c|c|c|c|c|c|}
\hline No. & Short name & Full name & $\begin{array}{l}\text { UniProtKB } \\
\text { ID }\end{array}$ & Classification & Note \\
\hline 1 & 4EBP1 & $\begin{array}{l}\text { Eukaryotic translation initiation } \\
\text { factor } 4 \mathrm{E} \text {-binding protein } 1\end{array}$ & Q13541 & translation factor & \\
\hline 2 & ADA & Adenosine deaminase & P00813 & deaminase & \\
\hline 3 & ARTN & Artemin & Q5T4W7 & neurotrophic factor & below LOD \\
\hline 4 & AXIN1 & Axin-1 & O15169 & G-protein modulator & \\
\hline 5 & BDNF & Brain-derived neurotrophic factor & $\mathrm{P} 23560$ & neurotrophic factor & $\begin{array}{l}\text { antibody } \\
\text { cross } \\
\text { activity }\end{array}$ \\
\hline 6 & BetaNGF & Beta-nerve growth factor & P01138 & neurotrophic factor & \\
\hline 7 & CASP8 & Caspase-8 & Q14790 & cysteine protease & \\
\hline 8 & CCL11 & Eotaxin & P51671 & chemokine & \\
\hline 9 & CCL13/MCP4 & $\begin{array}{l}\text { C-C motif chemokine } 13 / \text { Monocyte } \\
\text { chemotactic protein } 4\end{array}$ & Q99616 & chemokine & \\
\hline 10 & CCL19 & $\mathrm{C}-\mathrm{C}$ motif chemokine 19 & Q99731 & chemokine & \\
\hline 11 & CCL2/MCP1 & $\begin{array}{l}\mathrm{C}-\mathrm{C} \text { motif chemokine } 2 / \text { Monocyte } \\
\text { chemotactic protein } 1\end{array}$ & $\mathrm{P} 13500$ & chemokine & \\
\hline 12 & CCL20 & $\mathrm{C}-\mathrm{C}$ motif chemokine 20 & P78556 & chemokine & \\
\hline 13 & CCL23 & $\mathrm{C}-\mathrm{C}$ motif chemokine 23 & P55773 & chemokine & \\
\hline 14 & CCL25 & C-C motif chemokine 25 & O15444 & chemokine & \\
\hline 15 & CCL28 & C-C motif chemokine 28 & Q9NRJ3 & chemokine & \\
\hline 16 & CCL3/MIP1alpha & C-C motif chemokine 3 & $\mathrm{P} 10147$ & chemokine & \\
\hline 17 & CCL4 & C-C motif chemokine 4 & P13236 & chemokine & \\
\hline 18 & CCL7/MCP3 & $\begin{array}{l}\text { C-C motif chemokine } 7 / \text { Monocyte } \\
\text { chemotactic protein } 3\end{array}$ & P80098 & chemokine & \\
\hline 19 & CCL8/MCP2 & $\begin{array}{l}\text { C-C motif chemokine } 8 / \text { Monocyte } \\
\text { chemotactic protein } 2\end{array}$ & P80075 & chemokine & \\
\hline 20 & CD244 & Natural killer cell receptor 2B4 & Q9BZW8 & cell adhesion molecule & \\
\hline 21 & CD40 & $\begin{array}{l}\text { Tumor necrosis factor receptor } \\
\text { superfamily member } 5\end{array}$ & P25942 & tumor necrosis factor receptor & \\
\hline 22 & CD5 & T-cell surface glycoprotein CD5 & P06127 & oxidase & \\
\hline 23 & CD6 & T-cell differentiation antigen CD6 & $\begin{array}{l}\text { P30203/ } \\
\text { Q8WWJ7 }\end{array}$ & oxidase & \\
\hline 24 & CDCP1 & CUB domain-containing protein 1 & Q9H5V8 & transmembrane glycoprotein & \\
\hline 25 & CSF1 & Macrophage colony-stimulating factor 1 & P09603 & cytokine & \\
\hline 26 & CST5 & Cystatin-D & P28325 & cysteine protease inhibitor & \\
\hline 27 & CX3CL1 & Fractalkine & P78423 & chemokine & \\
\hline 28 & CXCL1 & Growth-regulated alpha protein & P09341 & chemokine & \\
\hline 29 & CXCL10 & $\mathrm{C}-\mathrm{X}-\mathrm{C}$ motif chemokine 10 & P02778 & chemokine & \\
\hline 30 & CXCL11 & $\mathrm{C}-\mathrm{X}-\mathrm{C}$ motif chemokine 11 & 014625 & chemokine & \\
\hline 31 & CXCL5 & $\mathrm{C}-\mathrm{X}-\mathrm{C}$ motif chemokine 5 & $\mathrm{P} 42830$ & chemokine & \\
\hline 32 & CXCL6 & $\mathrm{C}-\mathrm{X}-\mathrm{C}$ motif chemokine 6 & P80162 & chemokine & \\
\hline 33 & CXCL9 & $\mathrm{C}-\mathrm{X}-\mathrm{C}$ motif chemokine 9 & Q07325 & chemokine & \\
\hline 34 & DNER & $\begin{array}{l}\text { Delta and Notch-like epidermal } \\
\text { growth factor-related receptor }\end{array}$ & Q8NFT8 & growth factor & \\
\hline 35 & $\begin{array}{r}\text { EN-RAGE/ } \\
\text { S100A12 }\end{array}$ & Protein S100-A12 & P80511 & calmodulin & \\
\hline 36 & FGF19 & Fibroblast growth factor 19 & O95750 & growth factor & \\
\hline 37 & FGF21 & Fibroblast growth factor 21 & Q9NSA1 & growth factor & \\
\hline 38 & FGF23 & Fibroblast growth factor 23 & Q9GZV9 & growth factor & below LOD \\
\hline 39 & FGF5 & Fibroblast growth factor 5 & $\begin{array}{l}\text { P12034/ } \\
\text { Q8NF90 }\end{array}$ & growth factor & \\
\hline 40 & FLT3L & Fms-related tyrosine kinase 3 ligand & $\mathrm{P} 49771$ & cytokine & \\
\hline 41 & GDNF & Glial cell line-derived neurotrophic factor & P39905 & neurotrophic factor & \\
\hline 42 & $\mathrm{HGF}$ & Hepatocyte growth factor & P14210 & growth factor & \\
\hline 43 & IFNgamma & Interferon gamma & P01579 & interferon superfamily & below LOD \\
\hline 44 & IL10 & Interleukin-10 & P22301 & interleukin superfamily & \\
\hline 45 & IL10RA & Interleukin-10 receptor subunit alpha & Q13651 & defense/immunity protein & below LOD \\
\hline 46 & IL10RB & Interleukin-10 receptor subunit beta & Q08334 & defense/immunity protein & \\
\hline 47 & IL12B & Interleukin-12 subunit beta & P29460 & interleukin superfamily & below LOD \\
\hline 48 & IL13 & Interleukin-13 & P35225 & interleukin superfamily & below LOD \\
\hline 49 & IL15RA & Interleukin-15 receptor subunit alpha & Q13261 & cytokine receptor & below LOD \\
\hline
\end{tabular}


TABle 1. (CONTINUED)

\begin{tabular}{|c|c|c|c|c|c|}
\hline No. & Short name & Full name & $\begin{array}{l}\text { UniProtKB } \\
\quad I D\end{array}$ & Classification & Note \\
\hline 50 & IL17A & Interleukin-17A & Q16552 & interleukin superfamily & \\
\hline 51 & IL17C & Interleukin-17C & Q9P0M4 & chemokine & below LOD \\
\hline 52 & IL18 & Interleukin-18 & Q14116 & interleukin superfamily & \\
\hline 53 & IL18R1 & Interleukin-18 receptor 1 & Q13478 & type I cytokine receptor & \\
\hline 54 & IL1alpha & Interleukin-1 alpha & P01583 & interleukin superfamily & \\
\hline 55 & IL2 & Interleukin-2 & P60568 & interleukin superfamily & below LOD \\
\hline 56 & IL20 & Interleukin-20 & Q9NYY1 & interleukin superfamily & below LOD \\
\hline 57 & IL20RA & Interleukin-20 receptor subunit alpha & Q9UHF4 & defense/immunity protein & below LOD \\
\hline 58 & IL22RA1 & Interleukin-22 receptor subunit alpha-1 & Q8N6P7 & defense/immunity protein & below LOD \\
\hline 59 & IL24 & Interleukin-24 & Q13007 & interleukin superfamily & below LOD \\
\hline 60 & IL2RB & Interleukin- 2 receptor subunit beta & P14784 & type I cytokine receptor & below LOD \\
\hline 61 & IL33 & Interleukin-33 & O95760 & interleukin superfamily & \\
\hline 62 & IL4 & Interleukin-4 & P05112 & interleukin superfamily & below LOD \\
\hline 63 & IL5 & Interleukin-5 & P05113 & interleukin superfamily & below LOD \\
\hline 64 & IL6 & Interleukin-6 & P05231 & interleukin superfamily & \\
\hline 65 & IL7 & Interleukin-7 & P13232 & interleukin superfamily & \\
\hline 66 & IL8/CXCL8 & Interleukin-8 & P10145 & chemokine & \\
\hline 67 & KITLG/SCF & Kit ligand/Stem cell factor & P21583 & cell adhesion molecule & \\
\hline 68 & LIF & Leukemia inhibitory factor & P15018 & cytokine & \\
\hline 69 & LIFR & Leukemia inhibitory factor receptor & P42702 & cytokine & \\
\hline 70 & LTA/TNFB & Lymphotoxin-alpha/TNF-beta & P01374 & $\begin{array}{l}\text { tumor necrosis factor } \\
\text { family member }\end{array}$ & below LOD \\
\hline 71 & MMP1 & Interstitial collagenase & P03956 & $\begin{array}{l}\text { extracellular matrix } \\
\text { organization }\end{array}$ & \\
\hline 72 & MMP10 & Stromelysin-2 & P09238 & $\begin{array}{l}\text { extracellular matrix } \\
\text { organization }\end{array}$ & \\
\hline 73 & NRTN & Neurturin & Q99748 & neurotrophic factor & below LOD \\
\hline 74 & NTF3/NT3 & Neurotrophin-3 & P20783 & neurotrophic factor & below LOD \\
\hline 75 & OSM & Oncostatin-M & P13725 & interleukin superfamily & \\
\hline 76 & PDL1 & Programmed cell death 1 ligand 1 & Q9NZQ7 & $\begin{array}{l}\text { immunoglobulin receptor } \\
\text { superfamily }\end{array}$ & \\
\hline 77 & PLAU/uPA & Urokinase-type plasminogen activator & P00749 & serine protease & \\
\hline 78 & SIRT2 & NAD-dependent protein deacetylase sirtuin-2 & Q8IXJ6 & $\begin{array}{l}\text { chromatin/chromatin-binding } \\
\text { protein }\end{array}$ & \\
\hline 79 & SLAMF1 & Signaling lymphocytic activation molecule & Q13291 & cell adhesion molecule & below LOD \\
\hline 80 & STAMBP & STAM-binding protein & O95630 & cytokine & \\
\hline 81 & SULT1A1/ST1A1 & Sulfotransferase $1 \mathrm{~A} 1$ & P50225 & transferase & \\
\hline 82 & TGFalpha & Transforming growth factor alpha & P01135 & growth factor & \\
\hline 83 & $\begin{array}{l}\text { TGFB1/ } \\
\text { LAP-TGFbeta1 }\end{array}$ & $\begin{array}{l}\text { Latency-associated peptide Transforming } \\
\text { growth factor beta-1 }\end{array}$ & P01137 & growth factor & \\
\hline 84 & TNF & Tumor necrosis factor & $\mathrm{P} 01375$ & $\begin{array}{l}\text { tumor necrosis factor } \\
\text { family member }\end{array}$ & below LOD \\
\hline 85 & TNFRSF11B/OPG & $\begin{array}{l}\text { Tumor necrosis factor receptor superfamily } \\
\text { member } 11 \mathrm{~B} / \text { Osteoprotegerin }\end{array}$ & O00300 & $\begin{array}{l}\text { tumor necrosis factor } \\
\text { receptor }\end{array}$ & \\
\hline 86 & TNFRSF9 & $\begin{array}{l}\text { Tumor necrosis factor receptor } \\
\text { superfamily member } 9\end{array}$ & Q07011 & $\begin{array}{l}\text { tumor necrosis factor } \\
\text { receptor }\end{array}$ & \\
\hline 87 & TNFSF10/TRAIL & $\begin{array}{l}\text { Tumor necrosis factor ligand superfamily } \\
\text { member 10/TNF-related apoptosis-inducing } \\
\text { ligand }\end{array}$ & P50591 & $\begin{array}{l}\text { tumor necrosis factor } \\
\text { family member }\end{array}$ & \\
\hline 88 & TNFSF11/TRANCE & $\begin{array}{l}\text { Tumor necrosis factor ligand } \\
\text { superfamily member } 11\end{array}$ & O14788 & $\begin{array}{l}\text { tumor necrosis factor } \\
\text { family member }\end{array}$ & below LOD \\
\hline 89 & TNFSF12/TWEAK & $\begin{array}{l}\text { Tumor necrosis factor ligand } \\
\text { superfamily member } 12\end{array}$ & O43508 & $\begin{array}{l}\text { tumor necrosis factor } \\
\text { family member }\end{array}$ & \\
\hline 90 & TNFSF14 & $\begin{array}{l}\text { Tumor necrosis factor ligand } \\
\text { superfamily member } 14\end{array}$ & O43557 & $\begin{array}{l}\text { tumor necrosis factor } \\
\text { family member }\end{array}$ & \\
\hline 91 & TSLP & Thymic stromal lymphopoietin & Q969D9 & cytokine & \\
\hline 92 & VEGFA & Vascular endothelial growth factor A & P15692 & growth factor & \\
\hline
\end{tabular}

List of the proteins included in the 92-plex proximity extension assay PEA panel used in this study with UniProtKB ID, Full name, Short name, Classification, and Note, indicating the reason for excluding the protein from the final biomarker evaluation. One protein was excluded because of antibody cross-reactivity in the assay (BDNF). Another 22 proteins, according to Figure 2, did not meet our inclusion criterion of being above the limit of detection (LOD) in $\geq 4$ samples in $\geq 4$ patients and were also excluded, leaving 69 proteins for biomarker evaluation. 
Table 2. Patient Characteristics

\begin{tabular}{|c|c|c|c|c|c|c|c|c|c|c|}
\hline Case no. ID & $\begin{array}{c}1 \\
\text { T376 }\end{array}$ & $\begin{array}{c}2 \\
T 416\end{array}$ & $\begin{array}{c}3 \\
T 421\end{array}$ & $\begin{array}{c}4 \\
T 432\end{array}$ & $\begin{array}{c}5 \\
T 447\end{array}$ & $\begin{array}{c}6 \\
T 408\end{array}$ & $\begin{array}{c}7 \\
\text { T469 }\end{array}$ & $\begin{array}{c}8 \\
T 503\end{array}$ & $\begin{array}{c}9 \\
\text { T559 }\end{array}$ & $\begin{array}{c}10 \\
T 566\end{array}$ \\
\hline Gender & M & M & W & M & M & M & M & M & M & M \\
\hline Age (years) & 73 & 69 & 15 & 17 & 26 & 70 & 54 & 15 & 21 & 34 \\
\hline Mechanism of injury & MVA & Fall & MVA & MVA & MVA & MVA & Fall & MVA & Uncertain & MVA \\
\hline Coagulopathy & No & No & No & No & No & Warfarin & No & No & No & No \\
\hline GCS-M Admiss-ion & 4 & 5 & 5 & 4 & 5 & 5 & 1 & 5 & 5 & 5 \\
\hline GCS-M Discharge & 4 & 5 & 5 & 5 & 6 & 6 & 4 & 6 & 6 & 5 \\
\hline Length of stay in NIC (days) & 20 & 17 & 14 & 15 & 17 & 28 & 45 & 25 & 35 & 5 \\
\hline MD start (h post- TBI) & 26 & 45 & 51 & 11 & 26 & 9 & 17 & 19 & 38 & 9 \\
\hline GOSE & SD-L & GR-L & GR-L & SD-L & GR-H & GR-L & SD-L & SD-H & - & - \\
\hline
\end{tabular}

The table includes characteristics of the 10 individual patients. The age span reaches from 15 years to 73 years. Mechanism of injury was either motor vehicle accident (MVA) or fall. Presence of coagulopathy was noted preoperatively, either known anticoagulative medication (warfarin) or APTT/INR abnormality. The GCS-M (Glasgow Coma Scale-Motor score) was noted at admission and discharge. The length of stay at the neurointensive care (NIC) unit and start of microdialysis (MD) monitoring were recorded as well. The GOSE (Extended Glasgow Outcome Score) was recorded at a follow-up approximately six months after time of injury.

lower limit of detection (LOD). Any NPX values below LOD were replaced as LOD.

For all 92 assays included in the PEA inflammation panel, the mean intraassay variation assessed on linearized values was found to have a CV of 7\% (range 5-14\%) according to the manufacturer. For additional information on the panel performance, see Olink Inflammation-Validation Data (www.olink.com).

\section{Characteristics of panel proteins}

Table 1 lists the proteins included in the PEA inflammation panel. Additional information including protein function, source, and main current observation is provided in Supplementary Table 1.

\section{Statistical analysis}

Among the 92 proteins measured, one protein (BDNF) was excluded because of cross-reactivity in the antibody assay. Another 22 proteins did not meet our inclusion criteria of being above the LOD in $\geq 4$ samples in $\geq 4$ patients and therefore were also excluded, leaving 69 proteins for further statistical evaluation (see Results).
To study temporal dependence between the proteins, the protein expressions were standardized to mean 0 and standard deviation 1 after which cross-correlations were computed. ${ }^{22}$ Crosscorrelations show the dependence not only between protein measurements taken at the same time, but also between measurements taken at different time points, allowing study of the temporal protein dynamics. The cross-correlations were computed using the Spearman rank correlation coefficient to allow for nonlinear monotone relationships. ${ }^{23}$ Protein dependencies were visualized as a network.

The statistical analyses were performed using R 3.3.2. ${ }^{24}$ Networks for protein cross-correlations were plotted using the igraph package. $^{25}$

\section{Results}

\section{Characteristics of the patient cohort}

For demographic details, radiological findings and neurosurgical interventions, see Tables 2 and 3. Briefly, 10 patients ( 9 male and 1 female) with a mean age of 39 years (range 15-73 years) with

Table 3. Summary of Radiological Findings and Neurosurgical Interventions

\begin{tabular}{|c|c|c|c|c|c|c|c|c|c|c|}
\hline Case no. & $\begin{array}{c}1 \\
T 376\end{array}$ & $\begin{array}{c}2 \\
T 416\end{array}$ & $\begin{array}{c}3 \\
T 421\end{array}$ & $\begin{array}{c}4 \\
T 432\end{array}$ & $\begin{array}{c}5 \\
T 447\end{array}$ & $\begin{array}{c}6 \\
T 408\end{array}$ & $\begin{array}{c}7 \\
T 469\end{array}$ & $\begin{array}{c}8 \\
T 503\end{array}$ & $\begin{array}{c}9 \\
T 559\end{array}$ & $\begin{array}{c}10 \\
T 566\end{array}$ \\
\hline CT finding & Mixed & Mixed & $\mathrm{tSAH}$ & Contusion & Mixed & Mixed & Mixed & Contusion & Mixed & ASDH \\
\hline $\begin{array}{l}\text { Rotterdam } \\
\quad \text { CT score (1-6) }\end{array}$ & 4 & 3 & 4 & 5 & 5 & 4 & 5 & 2 & 4 & 2 \\
\hline Neurosurgical & $\mathrm{ICP}$ & ICP & ICP & ICP & ICP & ICP & ICP & $\mathrm{ICP}$ & ICP & ICP \\
\hline $\begin{array}{l}\text { monitoring/ } \\
\text { intervention }\end{array}$ & MD & MD & MD & $\begin{array}{l}\text { MD } \\
\text { DC }\end{array}$ & MD & MD & $\begin{array}{l}\text { MD } \\
\text { Contusion } \\
\text { evac. DC } \\
\text { thiopental }\end{array}$ & $\begin{array}{l}\text { MD } \\
\text { thiopental }\end{array}$ & MD & MD \\
\hline MD-probe location & Contusion & $\begin{array}{c}\text { Injured } \\
\text { lobe }\end{array}$ & $\begin{array}{r}\text { Normal } \\
\text { brain }\end{array}$ & $\begin{array}{c}\text { Injured } \\
\text { lobe }\end{array}$ & $\begin{array}{r}\text { Normal } \\
\text { brain }\end{array}$ & $\begin{array}{r}\text { Normal } \\
\text { brain }\end{array}$ & Injured lobe & $\begin{array}{c}\text { Injured } \\
\text { lobe }\end{array}$ & $\begin{array}{r}\text { Normal } \\
\text { brain }\end{array}$ & $\begin{array}{r}\text { Normal } \\
\text { brain }\end{array}$ \\
\hline Basal cisterns & 1 & 0 & 1 & 2 & 2 & 1 & 2 & 0 & 1 & 0 \\
\hline Midline shift & $0-5 \mathrm{~mm}$ & $0-5 \mathrm{~mm}$ & $0-5 \mathrm{~mm}$ & $0-5 \mathrm{~mm}$ & $0-5 \mathrm{~mm}$ & $0-5 \mathrm{~mm}$ & $0-5 \mathrm{~mm}$ & $0-5 \mathrm{~mm}$ & $0-5 \mathrm{~mm}$ & $0-5 \mathrm{~mm}$ \\
\hline
\end{tabular}

The computed tomography (CT) finding represents a subjective decision of the most striking intracranial pathology of the initial CT scan of the skull. The Rotterdam CT score of traumatic brain injury is a classification aimed at improving prognostic evaluation of patients admitted with acute traumatic brain injuries. It includes scores for compression of basal cisterns, amount of midline shift, epidural mass lesion, and intraventricular blood or traumatic subarachnoid hemorrhage (SAH). All patients received a microdialysis (MD) catheter as well as ICP (intracranial pressure) monitoring by either a Codman intraparenchymal pressure monitor or an intraventricular device (IVD). Other neurosurgical operative procedures including contusion evacuation, decompressive craniectomy (DC), or barbiturate coma (thiopental) were also indicated. The location of the MD catheter was recorded as being inside the injured part of the brain (injured lobe), in the injured lobe in close proximity to the main part of the brain injury (contusion), or placed in what appears on the CT to be a relatively uninjured part of the brain (normal brain). The basal cisterns compression and midline shift are noted separately but are also included in the Rotterdam CT score. $(0=$ normal, $1=$ partially compressed, $2=$ compressed $)$. Midline shift was within the $0-5 \mathrm{~mm}$ range for all patients. 

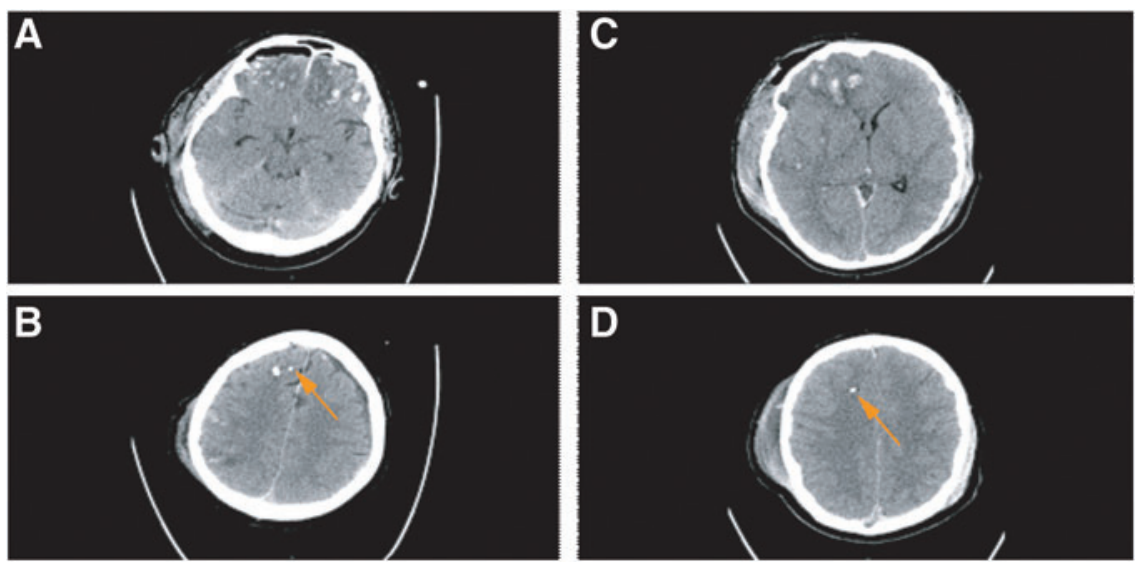

FIG. 1. Computed tomography $(\mathrm{CT})$ scans of Patient $2(\mathrm{~A}+\mathrm{B})$ and Patient $4(\mathrm{C}+\mathrm{D})$ showing the location of the microdialysis $(\mathrm{MD})$ membrane (orange arrows) as well as the type and extension of the brain tissue damage. The MD probe was placed in the vicinity but not within contusions. For further details, see Table 2. Color image is available online.

severe TBI were included. The dominant cause of injury was motor vehicle accident (MVA). The median GCS-M score was 5 (range 1-5), and the dominant CT finding was a mixed type of injury with a median Rotterdam CT score of 4 (range 2-5). The mean length of stay in the NIC unit was 22 days (range 5-45).

Figure 1 shows the CT images of two typical patients, including positioning of the MD catheter in relation to the injury. Systemic blood C-reactive protein (CRP) levels and body temperature during the time of biomarker sampling are presented in Supplementary Table 2 . On post-injury day 1 , nine patients had P-CRP above the reference limit $(<5 \mathrm{mg} / \mathrm{L})$. On days $2-6$, all patients had pathological C-CRP, and nine patients had levels $>100 \mathrm{mg} / \mathrm{L}$ on two to five occasions. Hyperthermia $\left(>38^{\circ} \mathrm{C}\right)$ was observed in five of the eight patients with available temperature data.

\section{Local brain energy metabolism and cellular distress status}

The routine low molecular weight biomarkers were analyzed bedside and were used to characterize the local burden of energy crisis and cellular distress in the brain tissue sampled with MD. Table 4 shows the estimated percentage of total monitoring time with critical biomarker levels for individual patients. Critical biomarker levels were measured during $10 \%$ or more of the monitoring time and were observed for MD-glucose in two patients (\#7 and 8), MD-LPR in two patients (\#4 and 9), MD-lactate in seven patients (\#1, 2, 4, 6, 8-10), MD-pyruvate in seven patients (\#1-4, 7,
$9,10)$, MD-glutamate in three patients $(\# 2,4,5)$, and MD-glycerol in eight patients (\#2-4, 6-10).

As summarized in Table 5, energy crisis of an ischemic type (high LPR and low pyruvate) occurred in two patients (\#4 and 9) without reaching glucose depletion. A more dominating feature was the burden of critically low pyruvate levels observed in five patients without high LPRs, indicative of non-ischemic energy perturbation (\#1-3, 7, 10). Signs of excitotoxicity (glutamate elevation) were present in three patients (\#2, 4, 5), whereas signs suggestive of membrane phospholipid degradation/oxidative stress (glycerol elevation) were a dominating feature in eight patients (\#2-4, 6-10).

\section{Inflammation protein profiling}

We used multiplex PEA technology to simultaneously measure 92 proteins in $1 \mu \mathrm{L}$ MD sample aliquots (Table 1). In brief, 23 interleukins, 21 chemokines, 13 growth factors, eight cytokines, and 27 other proteins were analyzed. As mentioned previously, BDNF was excluded because of cross-reactivity in the assay. Figure 2 shows the distribution of the remaining 91 proteins in respect to the detectability in individual patients. For instance, in 32 proteins-e.g., IL8 and VEGF A-protein levels were above in all samples, in all patients, while nine proteins-e.g., IL5 and TNFB-were below LOD in all samples.

Because of this variation in protein detectability, we defined an inclusion criterion to be fulfilled for further biomarker analysis-

Table 4. Local Brain Tissue Characteristics based on Routine Low Molecular Weight Biomarker Data

\begin{tabular}{|c|c|c|c|c|c|c|c|c|c|c|}
\hline Case no. & $\begin{array}{c}1 \\
\text { T376 }\end{array}$ & $\begin{array}{c}2 \\
T 416\end{array}$ & $\begin{array}{c}3 \\
T 421\end{array}$ & $\begin{array}{c}4 \\
T 432\end{array}$ & $\begin{array}{c}5 \\
T 447\end{array}$ & $\begin{array}{c}6 \\
T 408\end{array}$ & $\begin{array}{c}7 \\
T 469\end{array}$ & $\begin{array}{c}8 \\
T 503\end{array}$ & $\begin{array}{c}9 \\
T 559\end{array}$ & $\begin{array}{c}10 \\
\text { T566 }\end{array}$ \\
\hline Glucose $(<1 \mathrm{mmol} / \mathrm{L})$ & $3 \%$ & $0 \%$ & $6 \%$ & $0 \%$ & $0 \%$ & $0 \%$ & $43 \%$ & $10 \%$ & $9 \%$ & $0 \%$ \\
\hline LPR (>30) & $0 \%$ & $0 \%$ & $0 \%$ & $81 \%$ & $0 \%$ & $0 \%$ & $0 \%$ & $1 \%$ & $11 \%$ & $1 \%$ \\
\hline Lactate $(>4 \mathrm{mmol} / \mathrm{L})$ & $12 \%$ & $16 \%$ & $1 \%$ & $50 \%$ & $7 \%$ & $12 \%$ & $7 \%$ & $53 \%$ & $35 \%$ & $19 \%$ \\
\hline Pyruvate $(<120 \mu \mathrm{mol} / \mathrm{L})$ & $36 \%$ & $20 \%$ & $64 \%$ & $50 \%$ & $2 \%$ & $9 \%$ & $38 \%$ & $6 \%$ & $34 \%$ & $35 \%$ \\
\hline Glutamate $(>15 \mu \mathrm{mol} / \mathrm{L})$ & $0 \%$ & $65 \%$ & $0 \%$ & $60 \%$ & $75 \%$ & $1 \%$ & $2 \%$ & $1 \%$ & $6 \%$ & $9 \%$ \\
\hline Glycerol $(>100 \mu \mathrm{mol} / \mathrm{L})$ & $0 \%$ & $57 \%$ & $45 \%$ & $37 \%$ & $0 \%$ & $45 \%$ & $95 \%$ & $45 \%$ & $63 \%$ & $56 \%$ \\
\hline
\end{tabular}

Percent monitoring time with critical biomarker levels during the five days of microdialysis monitoring for the individual patients are given (bold values indicate critical levels for $10 \%$ of the monitoring time or more). Critical values for each biomarker are given in parenthesis based on $17-19$. LPR (lactate/pyruvate ratio). \% indicating percentage of monitoring time with critical biomarker level. 
Table 5. Local Brain Tissue Biomarker Patterns during Microdialysis Monitoring

\begin{tabular}{|c|c|c|c|c|c|c|c|c|c|c|}
\hline Case no. & $\begin{array}{c}1 \\
T 376\end{array}$ & $\begin{array}{c}2 \\
T 416\end{array}$ & $\begin{array}{c}3 \\
T 421\end{array}$ & $\begin{array}{c}4 \\
T 432\end{array}$ & $\begin{array}{c}5 \\
T 447\end{array}$ & $\begin{array}{c}6 \\
T 408\end{array}$ & $\begin{array}{c}7 \\
T 469\end{array}$ & $\begin{array}{c}8 \\
T 503\end{array}$ & $\begin{array}{c}9 \\
\text { T559 }\end{array}$ & $\begin{array}{c}10 \\
T 566\end{array}$ \\
\hline Ischemia & - & - & - & + & - & - & - & - & + & - \\
\hline Nonischemic energy crisis & + & + & + & + & - & - & + & - & + & + \\
\hline Excitotoxicity & - & + & - & + & + & - & - & - & - & - \\
\hline Membrane degr/ox stress & - & + & + & + & - & + & + & + & + & + \\
\hline
\end{tabular}

Local brain energy metabolism and cellular distress status suggested by the patterns of critical biomarker levels for the individual patients are given. Ischemia - energy crisis of an ischemic type (high lactate pyruvate ratio [LPR] and low pyruvate); nonischemic energy crisis—critically low pyruvate levels without high LPRs; excitotoxicity—critically high glutamate; membrane degr/ox stress—critically high glycerol levels suggesting membrane phospholipid degradation/oxidative stress.

i.e., protein levels needed to be above LOD in at least four samples $(\geq 10 \%)$ in at least four patients. This criterion excluded 22 proteins (IL13, ARTN, IL24, FGF23, IL20, NRTN, IL12B, IL20RA, IL15RA, IL2, IL10RA, TNF, SLAMF1, IL17C, IL2RB, IL22RA1, TRANCE, INFGamma, IL4, NT3, IL5, and TNFB), leaving 69 proteins for further statistical modeling.

Figure 3 demonstrates how these proteins were distributed according to their median protein level (median NPX value). For instance, MCP4 and CD 5 showed lowest protein NPX levels, whereas MCP1 and IL8 showed the highest levels (Fig. 3). Peak median values also occurred at different time points after trauma (Fig. 4). The earliest peaks were seen for STAMPB, IL10, and CXCL1 levels around one day after injury, whereas other proteins such as uPA, MCP3, and CD40 displayed late peaks, approximately five days after trauma.

Figure 5 shows the temporal trends in individual patients (and median NPX values) for CXCL10, CD40, and leukemia inhibitory factor (LIF), illustrating examples of different post-injury patterns. The corresponding graphs for all protein expression levels over time in individual patients are summarized in Supplementary Figure 1. Several proteins exhibited consistent trends of expression in all patients.

There were five generalized patterns of expression classified as early-, mid- or late peaking, biphasic (with one early and one late peak) or stable trends. For instance, CXCL10 showed a very strong and sustained pattern with a peak at approximately two to three days and a very late peak in a few patients. The CD40 levels were found to increase steadily over time, while LIF peaked very early around one day after trauma (Fig. 5). Table 6 provides a summary over median protein trends and peaks based on subjective visual inspection of the graphs in Supplementary Figure 1 (see online supplementary material at www.liebertpub.com).

\section{Visualization of temporal protein dynamics}

Because the protein expression levels were monitored over time (hours after TBI), it was possible to study the temporal dependence between different proteins using cross-correlations. One such example is illustrated in Figure 6, where it is demonstrated that the level of IL6 at one time point has a strong positive correlation with the level of LIF at the same time point, meaning that both proteins are highly expressed at the same time. Moreover, the correlation between the current level of IL6 and the level of LIF 30 hours later is strongly negative, meaning that if IL6 currently is highly expressed, LIF will tend to have a low expression level 30 hours later, and vice versa.

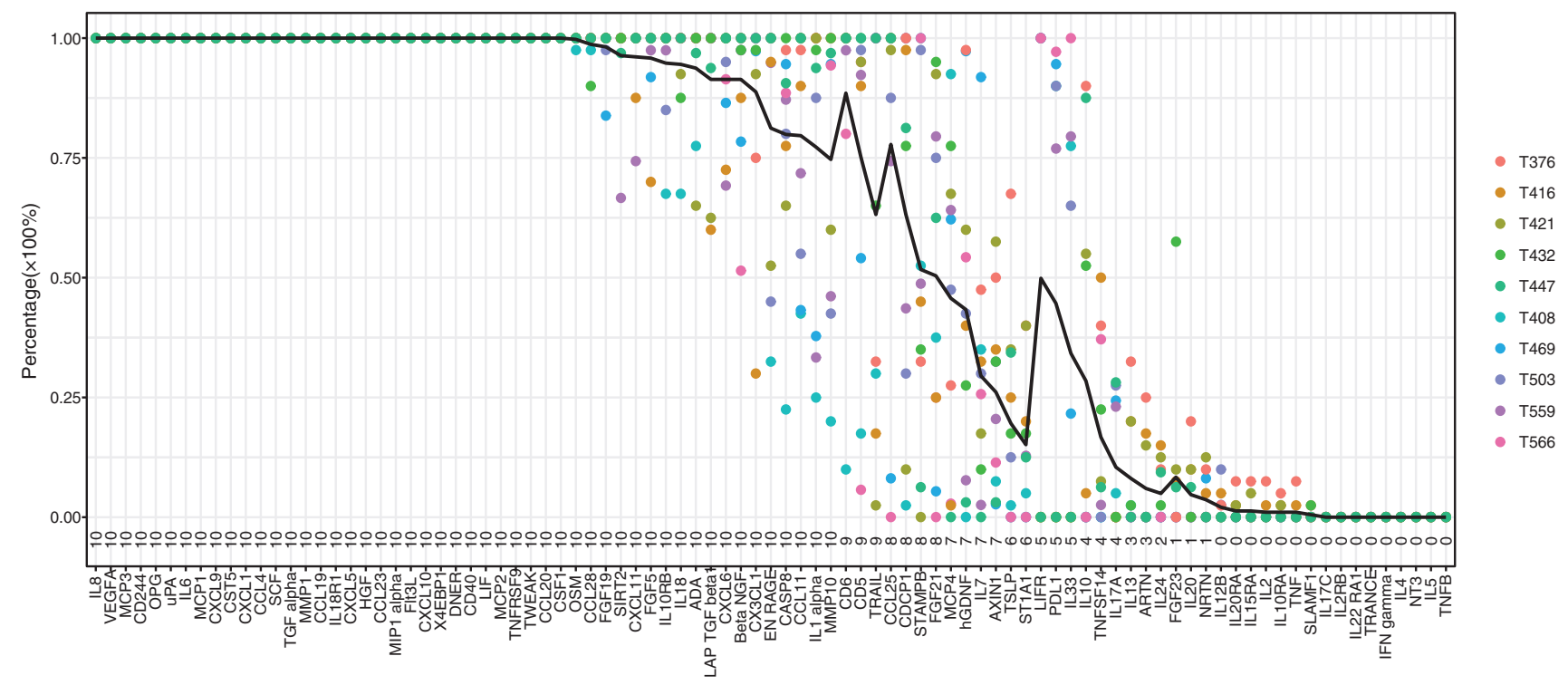

FIG. 2. Detectability of the 92 proteins included in the inflammatory proximity extension assay panel for the 10 individual patients with traumatic brain injury. Brain-derived neurotrophic factor (BDNF) was excluded from analysis because of cross-reactivity in the assay. Because of the variation in protein detectability, we introduced an inclusion criterion that protein levels needed to be above the limit of detection in at least four samples (i.e., $\geq 10 \%$ ) in at least four patients. This criterion excluded 22 proteins, leaving 69 proteins for further statistical modeling. Color image is available online. 


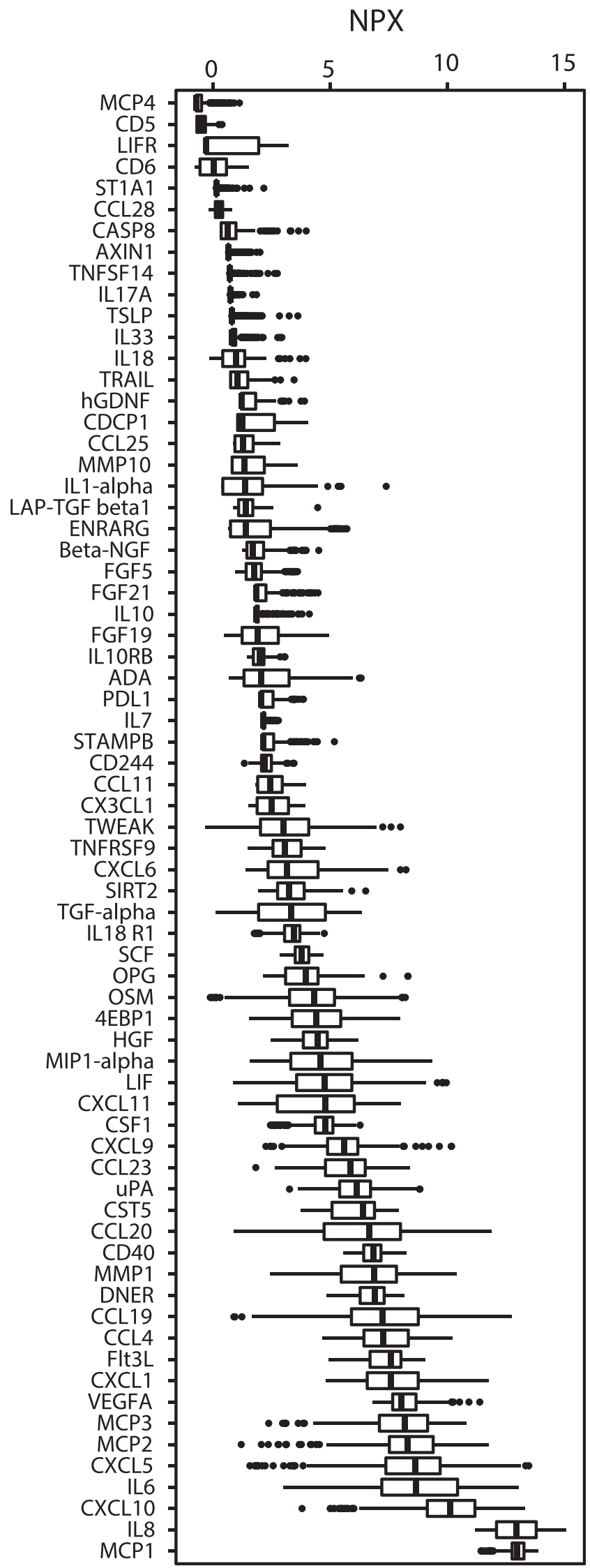

As also seen in Figure 6, the current IL6 level can be used to predict how the levels of LIF will develop over the course of the next $40 \mathrm{~h}$. Similar correlation data for a number of pairs of proteins are listed in Supplementary Figure 2.

To visualize the possibly regulatory relationships found among the proteins in this study, the proteins with the strongest temporal dependencies are shown as a network in Figure 7. The direction of the arrows in the network shows the temporal direction of the dependence between the proteins. For instance, the arrow from FGF19 to CCL4 suggests that the current expression level of FGF19 can be used to predict the future expression levels of CCL4. As seen in Figure 7, the proteins with by far the highest number of connections were LIF and CXCL5 with 13 and 12 connections (arrows), respectively, suggesting that these proteins have a central role in the inflammatory process. Next in line were MMP1 and CCL19 with six connections, followed by IL6, CXCL9, and OPG with five connections each.

\section{Discussion}

This is the first report on using highly sensitive multiplex PEA technology in combination with cerebral MD to measure simultaneously a large number of inflammatory proteins in very small sample volumes from brain interstitial fluid (ISF) in NIC patients with severe TBI. The study demonstrates in detail that TBI sets off a complex molecular cascade of proteins regulating inflammation in the injured brain. Some proteins are well known, such as IL6, IL8, MIP1 $\alpha$, whereas others have not been reported previously in human TBI, such as CCL8, -19, -20, -23, CXCL1, -5, -6, -9, -11, CST5, DNER, Flt3L, and SIRT2. Therefore, the study offers new insights in TBI-related neuroinflammation.

Proteins will be discussed in sections below based on detected protein NPX levels. In decreasing order MCP1, IL8, CXCL10, IL6, CXCL5, MCP2, MCP3, VEGF $\alpha$, CXCL1, Flt3L, CCL4, CCL19, DNER, MMP1, CD40, CCL20, CST5, uPA, CCL23, CXCL9, CSF1, CXCL11, LIF, MIP1a, were observed at high or very expression levels (median NPX $>5$ ). Comparing with the article by Helmy and colleagues, ${ }^{26}$ their five highest protein levels were seen for MCP1, CXCL10, PDGF $\alpha$ (not included in our panel), IL6, and IL8. Thus, even though the analytical methodology differs, some important core results remain similar, strengthening both studies.

Some of the proteins analyzed in this study previously have been implicated to play a role in the inflammatory response to TBI-i.e., MCP13, IL8, CXCL10, IL6, VEGF, CCL4, MMP1, CD40, uPA, and CSF1. The present study adds important information on the individual temporal profiles of these biomarkers in human TBI.

\section{Cytokines}

CC chemokines (CCLs). Many of the CCLs were regulated strongly in our study. The MCP1 (CCL2) is secreted by inflammatory cells (macrophages, monocytes), known to be involved in human TBI. $^{26,27}$ We found very high MCP1 expression levels (hovering at mean NPX $\sim 13$ ) and fairly sustained but with individual patient variations, supporting a very important role for this protein in human

FIG. 3. Illustration of how the 69 selected proteins were distributed according to their median protein levels-i.e., NPX (Neutralized Protein eXpression) value. The MCP4 and CD 5 displayed the lowest protein levels, whereas MCP1 and IL8 are presented with the highest levels. The thick black line of the boxplot corresponds to the median values, while each box represents from the first to third quartiles; the dots are the outliers. 


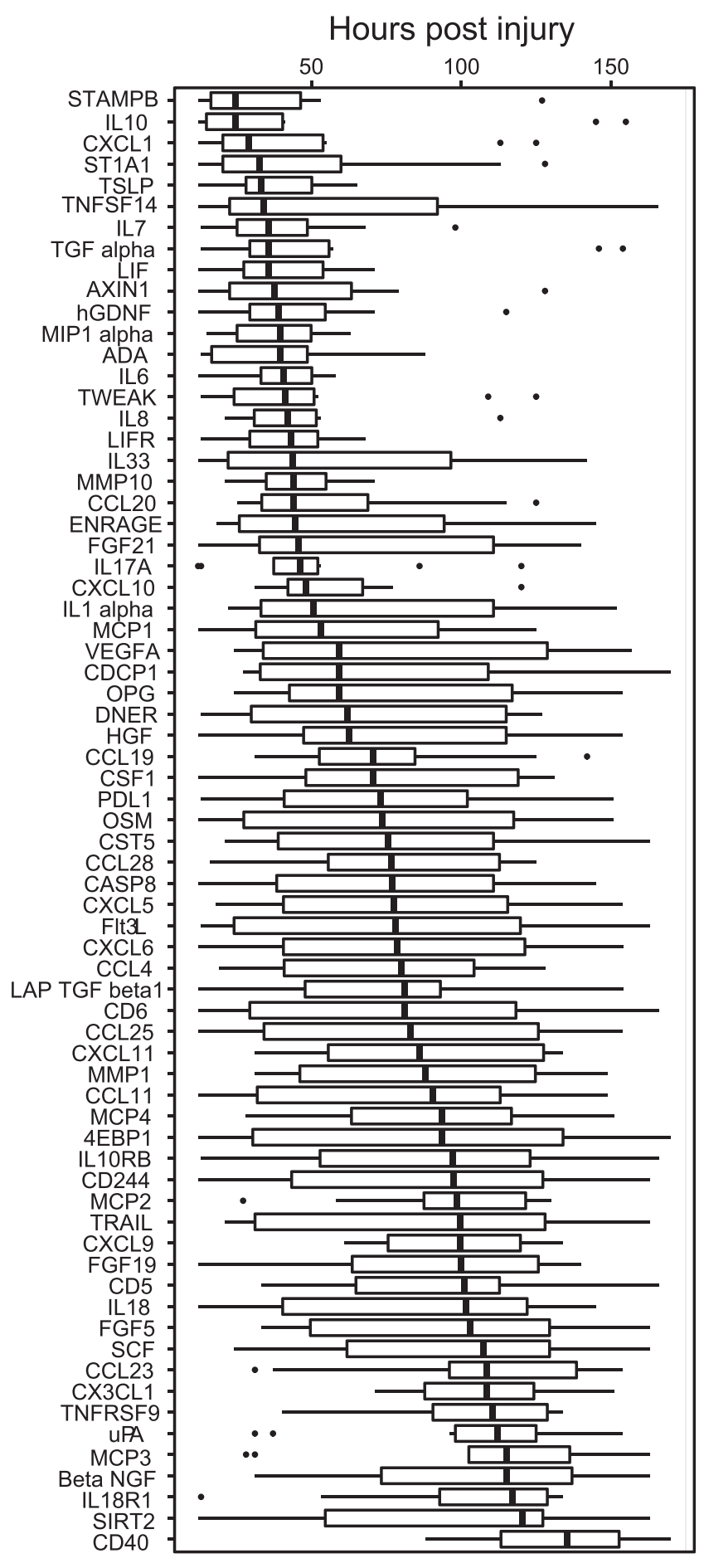

FIG. 4. Illustration of the peak values for the 10 patients occurring at different time points after trauma for the individual 69 proteins, providing sequential information about the changes in protein levels. For instance, the earliest peaks were seen in STAMPB, IL10, and CXCL1 approximately one day after injury, whereas proteins such as UPA, MP3, and CD40 peaked late approximately five days post-trauma. The thick black line of the boxplot corresponds to the median time points for the ten patients when the peak occurs, while each box represents from the first to third quartiles; the dots are the outliers.
TBI. In line with this notion, Helmy and associates ${ }^{26}$ found a 12 -fold higher median MCP1 level in MD compared with arterial plasma samples (i.e., a median ISF/plasma ratio of 12). Future studies need to focus on the correlation of MCP1 and outcome.

Regarding other MCPs-i.e., MCP2 (CCL8)—we observed very high levels of the protein that were fairly consistent between patients with a slightly increasing trend during the first $100 \mathrm{~h}$, followed by a decline in some patients, whereas others remained high. To our knowledge, MCP2 has not been reported previously in human TBI. The MCP3 (CCL7) binds to the receptors CCR1, CCR2, and CCR3 and is involved in chemotaxis and inflammatory responses. In the study by Helmy and coworkers, ${ }^{26}$ a fivefold higher median level in MD compared with arterial plasma samples (i.e., a median ISF/plasma ratio of $\sim 5$ ) was reported. We noticed a very strong $\mathrm{MCP} 3$ signal that was low initially in several patients, but later increased steadily over the observation period (up to median NPX 10), supporting that MCP3 may have a crucial role in the subacute phase after TBI.

The MCP4 (CCL13) was detected in much lower levels (mean NPX $<0$ ) but with individual variations. There seemed to be a peak of MCP4 in some patients at around $100 \mathrm{~h}$. The MIP $1 \alpha$ (CCL3) was detected initially at a high concentration (median NPX $\sim 7$ ), leveling off to fairly stable high levels (median NPX $\sim 4$ ). The MIP1 $\beta$ (CCL4), produced by e.g. microglia in response to TNF $\alpha$ and IL $1 \beta$ was described by Helmy and associates ${ }^{26}$ with a median ISF/plasma ratio of 2-3 and variable MD patterns with 6/12 patients peaking early $(<30 \mathrm{~h})$. In our study, we observed high CCL4 levels with a fairly stable trend during the monitoring period (median NPX 7-8). With CCL11, we noticed lower levels (median NPX 2.5), with large individual variations and an increasing trend at the end of the observation period.

The CCL19 plays a role in normal lymphocyte recirculation and homing. It binds specifically to chemokine receptor CCR7. We observed very high levels of CCL19 (median NPX 7.5) with mid peaks. The CCL20 has been suggested to play a crucial role in autoimmune pathogenesis of the central nervous system-e.g., multiple sclerosis. ${ }^{28}$ We observed high initial median levels (NPX 7.5), fairly sustained over time with delayed peaks in individual patients.

For CCL23, a chemokine with highly chemotactic activity for resting $\mathrm{T}$ cells and monocytes, we observed high levels with large individual differences initially followed by an increasing median trend with less individual variation during the second half of the monitoring period (median NPX 6-7). Increased blood levels of CCL23 have been observed recently in human ischemic stroke. ${ }^{29}$ The CCL25 was detected with much lower levels (median NPX $\sim 1.5$ ) but with an increasing trend over the observation period. With CCL28, we noticed much lower values (fluctuating at NPX 0.2), but with clear individual variations. Thus, the CCLs showed a diversity of temporal patterns, suggesting different roles of the members of this protein class in TBI.

CX chemokines (CXCLs). In the other large chemokine class (CX), we also noticed several interesting patterns of CXCLs not described previously in human TBI. We found a very strong regulation and high median levels of CXCL1, 5, 6, 9, 10, and 11. The CXCL1 and CXCL6 were biphasic with an early peak (within one day) and an increasing trend toward the end of the period at four to five days. The CXCL5, -9, and -11 showed a more prolonged flattened peak, whereas CXCL10 had one peak in the early phase ( $\sim 1-3$ days) after trauma at a median NPX level of $\sim 11$ with a trend for a late, slightly smaller peak.

To our knowledge, the expression pattern of CXCL1, -5, -6, -9, and -11 has not been reported previously after human TBI. The 

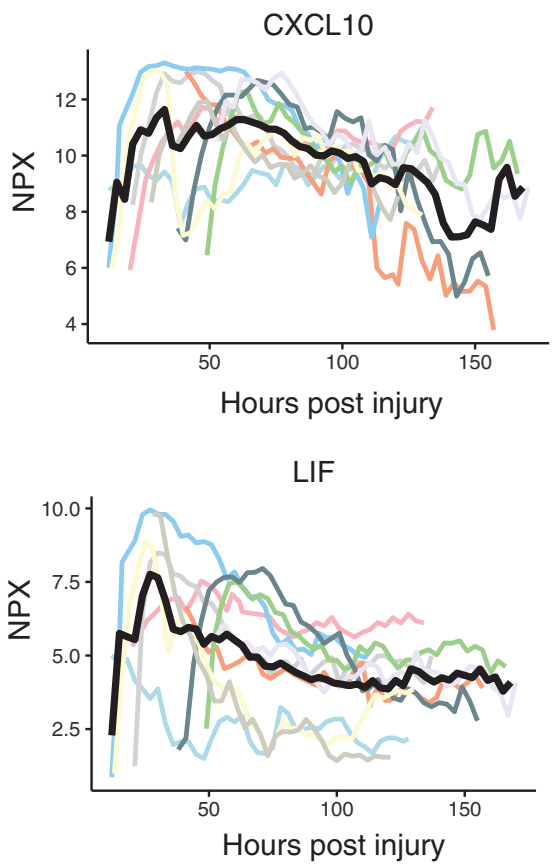

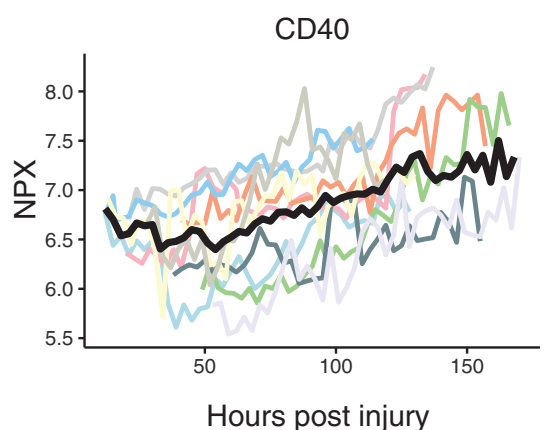

Hours post injury

FIG. 5. Examples of temporal expression level trends for three inflammatory proteins for the individual patients. The CXCL10 showed a very strong and sustained pattern with a peak at around two to three days with a trend toward a second peak late in the observation period. The CD40 showed a steadily increasing trend over time, whereas leukemia inhibitory factor (LIF) peaked very early, approximately one day after trauma. The black line represents the median expression level (NPX-Neutralized Protein eXpression). Color image is available online.

CXCL1, expressed by macrophages, neurotrophils, and epithelial cells, is involved in the recruitment of neutrophiles. The CXCL6 (GCP2) is also chemotactic for granulocytes with stronger activity compared with CXCL5.

Of great interest is CXCL10 (IP10), expressed by various brain cells (neurons, glial cells, macrophages) and with an important role in initiating neuroinflammation by controlling entry and recruitment of CXCR3+ immune cells (such as CD4+ Th1 and CD8+ Tcells, NK-cells, monocytes, and dendritic cells) into the injured brain. ${ }^{30,31}$ We have reported previously evidence of an important proinflammatory role of CXCL10 in a mouse model of focal TBI suggesting that this chemokine may be a potential target for antiinflammatory intervention. ${ }^{32,33}$ Helmy and coworkers ${ }^{26}$ also demonstrated the involvement of CXCL10 in human TBI with a peak in MD samples of TBI patients 1-3 days after injury at median ISF/plasma ratios of $10-15$, in line with our present human data. The delayed peak of CXCL10 demonstrated in both clinical studies appears attractive in a therapeutic context.

Table 6. Summary of Graphical Trends for Individual Proteins

\begin{tabular}{|c|c|c|c|c|c|c|c|c|c|}
\hline \multicolumn{2}{|c|}{ Early peak $<48 h$} & \multicolumn{2}{|c|}{ Mid peak $48-96 h$} & \multicolumn{2}{|c|}{ Late peak $96-150 h$} & \multicolumn{2}{|c|}{ Bi-phasic peak } & \multicolumn{2}{|c|}{ Stable } \\
\hline $\mathrm{ADA}$ & 4 & CCL19 & 8 & CCL11 & 6 & 4EBP1 & 7 & b-NGF & 2 \\
\hline CDCP1 & 2.4 & CCL28 & 0.3 & CCL23 & 7 & AXIN1 & 1.3 & CCL4 & 7 \\
\hline ENRAGE & 4 & CXCL11 & 4.5 & CCL25 & 1.8 & CCL20 & 8 & CD5 & -0.5 \\
\hline hGDNF & 2 & CXCL5 & 8 & $\mathrm{CD} 244$ & 3 & CASP8 & 1.7 & CSF1 & 4.8 \\
\hline IL17A & 0.9 & CXCL9 & 6 & CD40 & 7.5 & CCL11 & 3.3 & CX3CL1 & 2.5 \\
\hline IL33 & 2.1 & MMP1 & 7 & CD6 & 1.2 & CXCL1 & 11 & DNER & 7 \\
\hline IL7 & 2.3 & OPG & 4.5 & CST5 & 7 & CXCL10 & 11 & FGF19 & 2 \\
\hline LIF & 7.5 & PDL1 & 2.5 & CXCL6 & 6 & CXCL6 & 4 & FGF5 & 2.3 \\
\hline LIFR & 1.8 & & & Flt3L & 8.5 & FGF21 & 2.6 & $\mathrm{HGF}$ & 4.5 \\
\hline MIP1a & 7 & & & MCP2 & 11 & IL10 & 2.9 & IL1a & 2 \\
\hline MMP10 & 2 & & & MCP3 & 10 & IL18 & 1.9 & IL10RB & 2 \\
\hline STAMPB & 4 & & & MCP4 & 0.0 & IL6 & 10 & IL18R1 & 3.5 \\
\hline TGFa & 5 & & & TNFRSF9 & 4 & IL8 & 14.8 & LAPTGFb & 1.5 \\
\hline TNFSF14 & 1.2 & & & $\mathrm{uPA}$ & 6.5 & MMP1 & 7 & MCP1 & 13 \\
\hline TRAIL & 2 & & & & & OSM & 5.5 & SCF & 3.7 \\
\hline TSLP & 1.5 & & & & & SIRT2 & 5 & ST1A1 & $<1$ \\
\hline TWEAK & 6 & & & & & & & VEGFa & $8-9$ \\
\hline
\end{tabular}

Early ( $<48 \mathrm{~h}$ after injury)-, mid (48-96h)-, late (96-150h) peaks, biphasic (early/late), and stable median trends as well as median peak NPX (Neutralized Protein eXpression) values are given based on visual inspection of the graphs in the order they appear in Supplementary Figure 1. An increase of 1 NPX represents a two-fold increase of protein concentration in the sample. 
Spearman correlation between IL-6 and LIF

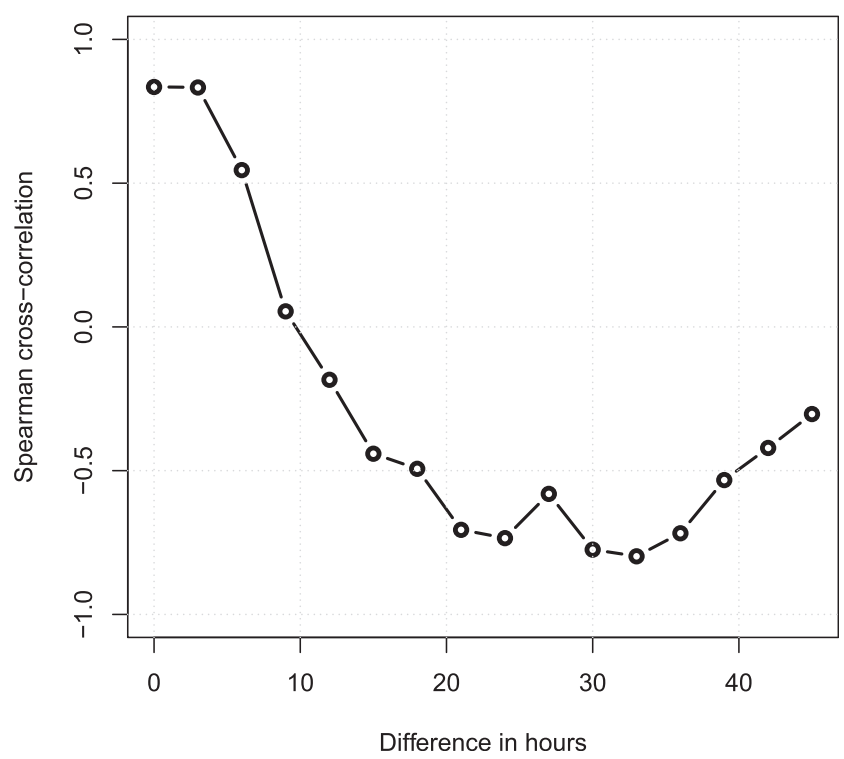

FIG. 6. To study the temporal dependence between the individual proteins, cross-correlations were computed ${ }^{22}$ using the Spearman rank correlation coefficient. ${ }^{23}$ This is one example showing that the level of interleukin (IL)6 at one time point has a strong positive correlation with the level of leukemia inhibitory factor (LIF) at the same time point-i.e., both proteins are highly expressed at the same time. Moreover, the correlation between the current level of IL6 and the level of LIF $30 \mathrm{~h}$ later is strongly negative, meaning that if IL6 currently is highly expressed, LIF will be having a low expression level $30 \mathrm{~h}$ later, and vice versa, enabling a prediction of the levels of LIF over the course of the next $40 \mathrm{~h}$ based on the current IL6 level.

Proteins involved in maintaining inflammatory responses are also of special interest. The CX3CL1/fractalkinem, which is found throughout the brain in neuronal cells and is upregulated by $\mathrm{TNF} \alpha$ and IL1 $\beta$ in astrocytes with its receptor on microglia and astrocytes, may have such a role. ${ }^{34}$ We measured medium-high levels of CX3CL1 (median NPX 2.5) with large variation between patients after trauma. In the study by Helmy and colleagues, ${ }^{26} \mathrm{CX} 3 \mathrm{CL} 1$ median ISF/plasma ratios of $\sim 2$ with no peaks were reported. Further studies need to elucidate the role of this protein in TBI.

Other cytokines. There were several other interesting proteins affected by the injury. The LIF is involved in neuronal cell differentiation and inflammation by activation of JAK/STAT and MAP kinases. We noticed a high early LIF peak (median NPX 7.5) slowly leveling off to a median NPX level of $\sim 5$, suggesting that LIF is an important mediator of inflammatory reactions elicited by the trauma.

The LIF receptor (LIFR) was detected at much lower levels but with a clear decreasing trend. The highest LIFR values were observed at MD start (median NPX below 2) in five of 10 patients followed by a gradual decline. In five patients, however, LIFR levels were close to LOD for unknown reasons, making interpretation of temporal LIF/LIFR ratios difficult.

OncostatinM (OSM) is related to LIF and regulates production of other cytokines (IL6, GCSF, and MCPs) in endothelial cells. We noticed a biphasic trend for OSM, with a high initial peak followed by a decline and a later peak, median NPX values residing in the 4-6 span.

Stem cell factor (SCF/Kit ligand) is a multi-functional cytokine important for cell survival and proliferation, acting synergistically with other cytokines. We noticed medium high NPX levels $(\sim 3.6-4)$ with individual fluctuations but no clear trend during the observation period. Further studies are needed to demonstrate whether there are any changes in the concentration levels for this protein at later time points.

The CD40 is a member of the TNF-receptor superfamily. It is found on antigen presenting cells where, on binding of its ligand CD40L, stimulates them and induces a broad variety of immune and inflammatory responses. The CD40L has been implicated in human TBI. ${ }^{35}$ Helmy and associates ${ }^{26}$ showed individual CD40L variation among TBI patients with an early $(<40 \mathrm{~h})$ peak in four of 12 patients. We observed high CD40 levels with a steadily increasing temporal trend within the median NPX 6.5-7.5 span.

\section{Interleukins}

Many of the interleukins were undetectable or were detected in very low concentrations/low number of samples (i.e., IL2, IL2RB, IL4, IL5, IL10RA, IL12B, IL13, IL15RA, IL17C, IL20, IL20RA, IL22RA1, IL24). We found a strong biphasic regulation of IL8 (CXCL8), however, with a very high early peak (median NPX 15) within the first day post-TBI followed by a decrease and a secondary peak in the end of the observation period at four to five days (median NPX 14).

The IL8 is produced by many cells including macrophages, endothelial cells, or any cells with toll-like receptors and is part of the innate immune response. It is regulated by many factors (e.g., $\mathrm{NF} \kappa \mathrm{B}$ ), and the high levels in our study may imply an important role of this protein in neutrophil recruitment after TBI. The biphasic trend may suggest a first peak involved in chemotaxis and a second peak involved in phagocytosis of injured cells. In the study by Helmy and coworkers, ${ }^{26}$ a very high median ISF/plasma ratio of 20 was reported, supporting intrathecal production.

The IL6 is a cytokine with a wide variety of biological functions. It is a potent inducer of the acute phase response and plays an essential role in the final differentiation of B-cells into Ig-secreting cells. Involved in lymphocyte and monocyte differentiation, IL6 acts on B-cells, T-cells, hepatocytes, hematopoietic progenitor cells, and cells of the central nervous system (CNS) and is required for the generation of $\mathrm{T}(\mathrm{H}) 17$ cells.

The IL6 is a strong inducer of the inflammatory response after TBI, but also has neuroprotective properties. ${ }^{36,37}$ In the study by Helmy and colleagues, ${ }^{26}$ an early ISF peak was observed in nine of 12 patients with TBI during the first three to four days after injury, but no late peaks were reported. Again, a very high median ISF/plasma ratio of 35 was observed, indicative of a substantial intrathecal IL6 production. In 57 patients with severe TBI, Mellergård and associates ${ }^{38}$ reported the highest ISF levels of IL6 in the first 24-h MD sample, then declining levels over the remaining observation period (days 2-7 after injury).

In our study, we found a biphasic median trend with a high flat peak (NPX 10) over the first two days after injury followed by a decline and a second peak (median NPX 9) toward the end of the monitoring period. Based on the previous studies ${ }^{26,38}$ showing no secondary IL6 peaks and the fact that half of our patients showed a continued decline over the monitoring period (even though the group median showed a peak), our results suggest that delayed IL6 peaks may only present in a subpopulation of patients with TBI.

The anti-inflammatory IL10 was reported to respond late to human TBI in the study by Helmy and associates. ${ }^{26}$ Thus, presenting at a median ISF/Plasma ratio of $\sim 4$, IL10 levels were observed peaking in $5 / 12$ patients with TBI at four to six days post- 


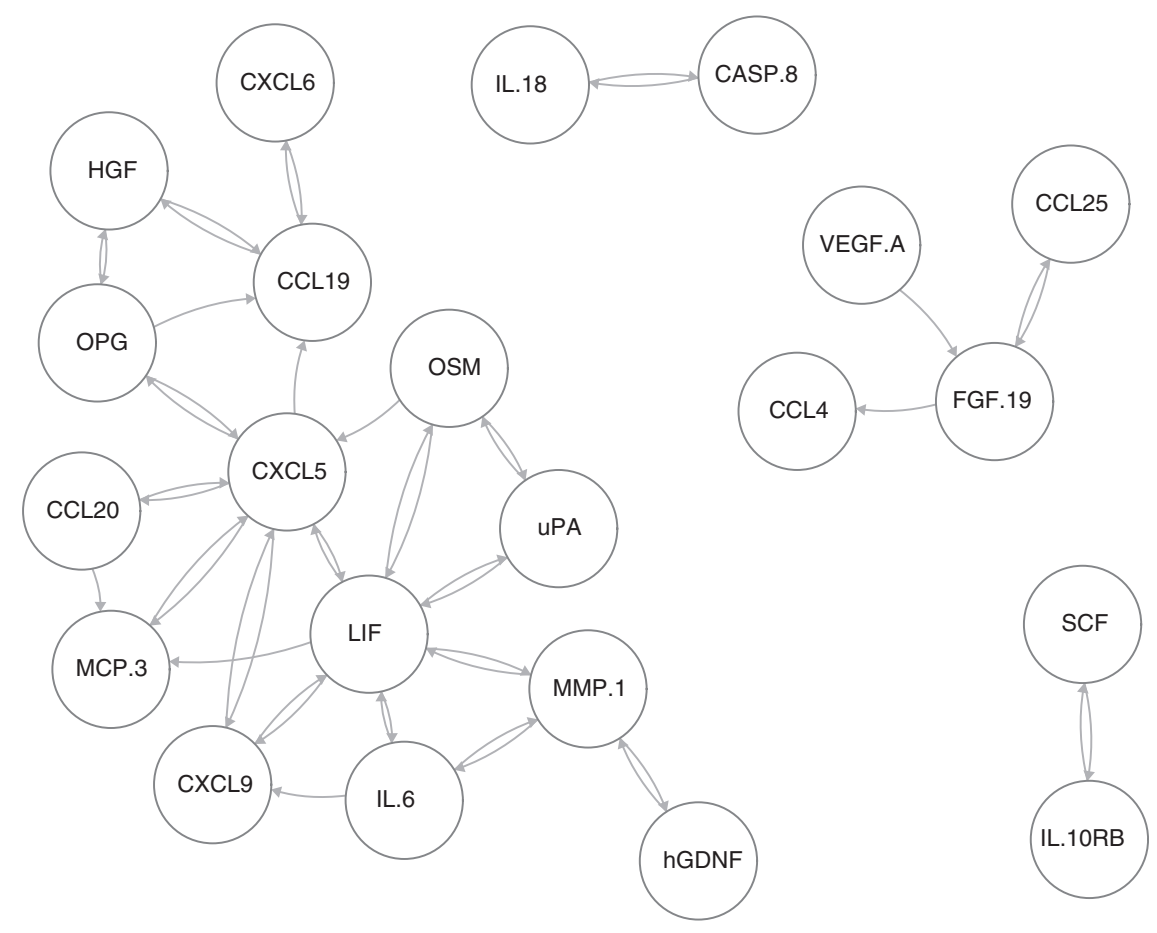

FIG. 7. Network of potentially regulatory relationships for the proteins with the strongest temporal dependencies according to the cross-correlation analysis is shown. The direction of the arrows in the network shows the temporal direction of the dependence between the proteins. For instance, the arrow from FGF19 to CCL4 shows that the current expression level of FGF19 can be used to predict the future expression levels of CCL4. The proteins with by far the highest number of connections (arrows) were LIF and CXCL5 (13 and 12 , respectively), suggesting that these proteins have a central role in the inflammatory process. Next in line were MMP1 and CCL19 (six connections) and IL6, CXCL9, OPG with five connections each.

injury. In our study, IL10 was detectable only in 4/10 patients with an early peak in two patients and a late peak in another two patients starting at four days after injury. This is not in complete agreement with the results in the study by Mellergard and colleagues ${ }^{38}$ who reported low stable median ISF levels of IL10 without significant peaks as measured days two to seven in 57 patients with severe TBI.

\section{Proteases}

The MMP1 is involved in breakdown of the blood-brain-barrier (BBB) and the development of edema after injury. In a recent MD study in 12 patients with contusions, MMP1 remained fairly stable and at low levels using Luminex technology. ${ }^{39}$ In our measurements, MMP1 was detected at high levels with a biphasic peak (median NPX 7). The MMP10 levels were observed to have a different trend, with lower values, peaking at one to two days (median NPX 2) and then subsiding. This pattern differed from that in the study by Guilfoyle and coworkers $^{39}$ who reported low and stable values of MMP10, suggesting that the PEA method may be more sensitive for detection of MMPs in MD samples compared with Luminex technology.

In another study of eight patients with TBI, Roberts and associates $^{40}$ also found early MD peaks of MMP1, but after two days the levels decreased and remained stable at low levels. The studies combined suggest that MMP1 and perhaps MMP10 are involved in pathological events after trauma such as breakdown of BBB and edema formation.

Urokinase (uPA) is a serine protease that activates plasminogen to plasmin. This activation leads to a proteolytic cascade that ultimately is important for the degradation of tissue and thrombolysis. We found a slowly increasing trend at a high expression level (median NPX >5). Interestingly, uPA has been suggested to be involved in progression of contusional bleedings after $\mathrm{TBI}^{41}$ and delayed intracerebral bleedings after murine closed head TBI. ${ }^{42}$

Cystatin D (CST5) is a cysteine proteinase inhibitor found in human saliva and tear fluid and may play a role in controlling proteolytic activity during inflammatory processes. This biomarker was selected as the best biomarker for TBI in the article by Hill and coworkers ${ }^{43}$ because it was regulated at very early stages and could discriminate between mild and severe injury. In our study, we observed high levels of the protein (median NPX 6-7), which was stable for most patients, while a slightly increasing trend could be observed for some patients in the end of the observation period (Supplementary Fig.1; see online supplementary material at www.liebertpub.com).

\section{Growth factors}

Macrophage colony stimulating factor 1 (CSF1) is a cytokine and a growth factor that functions as an inducer of proliferation and differentiation of hematopoietic stem cells to macrophages and monocytes. The CSF1 plays an important role in innate immunity, inflammation, osteogenesis, and fertility. The CSF1 have been linked to M2 microglia, ${ }^{41,44}$ although the concept of M1/M2 microglia in TBI remains unclear. ${ }^{45}$ We saw stable high levels of CSF1 with a median NPX of $\sim 5$ in $9 / 10$ patients. Another M2 stimulator, IL4, was not detectable in our study.

Increased levels of vascular endothelial growth factor (VEGF) have been reported previously in $\mathrm{CSF}^{46}$ and MD samples. ${ }^{47}$ Helmy and colleagues ${ }^{26}$ reported a VEGF median ISF/plasma ratio of $\sim 8$ without any peaks. We observed fairly stable high VEGF median levels (NPX $\sim 8$ ) with three patients showing very high peaks (NPX >8) appearing in the early, middle, and late phase of the monitoring period, respectively. Mellegård and associates ${ }^{47}$ 
reported an ISF peak of VEGF in the second of six 6-h periods after implantation of a MD catheter in seven patients with TBI.

Delta and notch-like epidermal growth factor-related receptor (DNER) is an activator of the NOTCH1 pathway. Notch receptors have been shown to regulate the expression of proteins that are crucial for peripheral T-cell activation and differentiation, including the transcription factors nuclear factor- $\kappa \mathrm{B}(\mathrm{NF}-\kappa \mathrm{B})$, the proinflammatory cytokine interferon- $\gamma$ (IFN $\gamma$ ), and the interleukin-4 (IL4) enhancer CNS2. ${ }^{48}$ We observed high levels of DNER (median NPX $\sim 7$ ) with large variations in patterns and trends among the patients, suggesting an important role for DNER mediated signaling in TBI.

\section{Cross-correlations}

Because the protein expression levels were monitored over time after TBI, it was possible to study the temporal dependence between different proteins using cross-correlations. The data in Figure 6 and Supplementary Figure 1 reveal strong relationships among the proteins and show that suitably chosen proteins can be monitored to discover (and possibly interfere with) changes in the levels of other proteins hours or days before the changes occur.

A high cross-correlation between two proteins could indicate a direct or indirect regulatory relationship between them, but such crosscorrelation could also be because both proteins may be regulated by some external mechanism not included in our data. Indeed, in the example of IL6 and LIF (Fig. 6), the relationship could be explained by the fact that both proteins are decreasing over time. Nevertheless, such relationships are interesting because they may allow us to predict what will happen with the expression levels of some downstream proteins by measuring only a few upstream proteins in the inflammatory cascade.

To visualize the possible regulatory relationships found among the proteins in this study, the proteins with the strongest temporal dependencies are shown as a network in Figure 7. The direction of the arrows in the network shows the temporal direction of the dependence between the proteins. For instance, the arrow from FGF19 to CCL4 shows that the current expression level of FGF19 can be used to predict the future expression levels of CCL4. As illustrated in Figure 7, the proteins with by far the highest number of connections were LIF and CXCL5, suggesting that these proteins have a central role in the inflammatory process.

\section{Study limitations}

Despite the fact that the data presented here are based on a small cohort of patients with TBI, we believe that the study brings out new valuable knowledge on the temporal profiles and patterns of potentially important biomarkers of inflammation in human TBI, where both previously studied and novel proteins were analyzed.

Even though the analytical method is semiquantitative, it has proven very potent with high sensitivity and specificity allowing for analyzing extremely small samples such as microdialysates, thus providing valuable comparable data on a large number of proteins useful for studying temporal levels and trends to help monitoring patterns of complex injury mechanism in CNS disease. Once a smaller number of key biomarkers have been identified, a PEA-based platform can be implemented as a quantitative method for routine use in the NIC setting.

\section{Acknowledgment}

The authors are sincerely grateful to the nurses and staff of the NIC unit for running the bedside microdialysis and to Inger Ståhl Myllyaho for excellent technical assistance. The study was supported financially by Uppsala University Hospital, Uppsala County Council (Region Uppsala), the Centre of Excellence Neurotrauma, the Swedish Research Council, the Vinnova Foundation, the Uppsala Berzelii Technology Centre for Neurodiagnostics, Marie Curie ITN (GastricGlycoExplorer) and the Selander Foundation.

\section{Author Disclosure Statement}

No competing financial interests exist.

\section{Supplementary Material}

Supplementary Figure S1

Supplementary Figure S2

Supplementary Table S1

Supplementary Table S2

\section{References}

1. Masel, B.E. and DeWitt, D.S. (2010). Traumatic brain injury: a disease process, not an event. J. Neurotrauma 27, 1529-1540.

2. Puntambekar, S.S., Saber, M., Lamb, B.T., and Kokiko-Cochran, O.N. (2018). Cellular players that shape evolving pathology and neurodegeneration following traumatic brain injury. Brain Behav. Immun. 71, 9-17.

3. Zeiler, F.A., Thelin, E.P., Czosnyka, M., Hutchinson, P.J., Menon, D.K.. and Helmy, A. (2017). Cerebrospinal fluid and microdialysis cytokines in severe traumatic brain injury: a scoping systematic review. Front. Neurol. 8, 331.

4. Hutchinson, P.J., O’Connell, M.T., Nortje, J., Smith, P., Al-Rawi, P.G., Gupta, A.K., Menon, D.K.. and Pickard, J.D. (2005). Cerebral microdialysis methodology-evaluation of $20 \mathrm{kDa}$ and $100 \mathrm{kDa}$ catheters. Physiol. Meas. 26, 423-428.

5. Hillman, J., Aneman, O., Anderson, C., Sjogren, F., Saberg, C.. and Mellergard, P. (2005). A microdialysis technique for routine measurement of macromolecules in the injured human brain. Neurosurgery $56,1264-1268$.

6. Dahlin, A.P., Wetterhall, M., Caldwell, K.D., Larsson, A., Bergquist, J., Hillered, L.. and Hjort, K. (2010). Methodological aspects on microdialysis protein sampling and quantification in biological fluids: an in vitro study on human ventricular CSF. Anal. Chem. 82, 4376-4385.

7. Darmanis, S., Nong, R.Y., Hammond, M., Gu, J., Alderborn, A., Vanelid, J., Siegbahn, A., Gustafsdottir, S., Ericsson, O., Landegren, U., and Kamali-Moghaddam, M. (2010). Sensitive plasma protein analysis by microparticle-based proximity ligation assays. Mol. Cell. Proteomics 9, 327-335.

8. Landegren, U., Vanelid, J., Hammond, M., Nong, R.Y., Wu, D., Ulleras, E., and Kamali-Moghaddam, M. (2012). Opportunities for sensitive plasma proteome analysis. Anal. Chem. 84, 1824-1830.

9. Darmanis, S., Gallant, C.J., Marinescu, V.D., Niklasson, M., Segerman, A., Flamourakis, G., Fredriksson, S., Assarsson, E., Lundberg, M., Nelander, S., Westermark, B., and Landegren, U. (2016). Simultaneous multiplexed measurement of RNA and proteins in single cells. Cell Rep. $14,380-389$.

10. Hillered, L., Dahlin, A.P., Clausen, F., Chu, J., Bergquist, J., Hjort, K., Enblad, P., and Lewen, A. (2014). Cerebral microdialysis for protein biomarker monitoring in the neurointensive care setting - a technical approach. Front. Neurol. 5, 245.

11. Elf, K., Nilsson, P., and Enblad, P. (2002). Outcome after traumatic brain injury improved by an organized secondary insult program and standardized neurointensive care. Crit. Care Med. 30, 2129-2134.

12. Lavoie, A., Moore, L., LeSage, N., Liberman, M., and Sampalis, J.S. (2004). The New Injury Severity Score: a more accurate predictor of inhospital mortality than the Injury Severity Score. J. Trauma 56, 1312-1320.

13. Wilson, J.T., Pettigrew, L.E., and Teasdale, G.M. (1998). Structured interviews for the Glasgow Outcome Scale and the extended Glasgow Outcome Scale: guidelines for their use. J. Neurotrauma 15, 573-585.

14. Maas, A.I., Steyerberg, E.W., Marmarou, A., McHugh, G.S., Lingsma, H.F., Butcher, I., Lu, J., Weir, J., Roozenbeek, B., and Murray, G.D. (2010). IMPACT recommendations for improving the design and analysis of clinical trials in moderate to severe traumatic brain injury. Neurotherapeutics 7, 127-134.

15. Marklund, N., Farrokhnia, N., Hanell, A., Vanmechelen, E., Enblad, P., Zetterberg, H., Blennow, K., and Hillered, L. (2014). Monitoring of beta-amyloid dynamics after human traumatic brain injury. J. Neurotrauma 31, 42-55. 
16. Ronne-Engstrom, E., Cesarini, K.G., Enblad, P., Hesselager, G., Marklund, N., Nilsson, P., Salci, K., Persson, L., and Hillered, L. (2001). Intracerebral microdialysis in neurointensive care: the use of urea as an endogenous reference compound. J. Neurosurg. 94, 397-402.

17. Schulz, M.K., Wang, L.P., Tange, M., and Bjerre, P. (2000). Cerebral microdialysis monitoring: determination of normal and ischemic cerebral metabolisms in patients with aneurysmal subarachnoid hemorrhage. J. Neurosurg. 93, 808-814.

18. Reinstrup, P., Stahl, N., Mellergard, P., Uski, T., Ungerstedt, U., and Nordstrom, C.H. (2000). Intracerebral microdialysis in clinical practice: baseline values for chemical markers during wakefulness, anesthesia, and neurosurgery. Neurosurgery 47, 701-709.

19. Hutchinson, P.J., Jalloh, I., Helmy, A., Carpenter, K.L., Rostami, E., Bellander, B.M., Boutelle, M.G., Chen, J.W., Claassen, J., DahyotFizelier, C., Enblad, P., Gallagher, C.N., Helbok, R., Hillered, L., Le Roux, P.D., Magnoni, S., Mangat, H.S., Menon, D.K., Nordstrom, C.H., O'Phelan, K.H., Oddo, M., Perez Barcena, J., Robertson, C., Ronne-Engstrom, E., Sahuquillo, J., Smith, M., Stocchetti, N., Belli, A., Carpenter, T.A., Coles, J.P., Czosnyka, M., Dizdar, N., Goodman, J.C., Gupta, A.K., Nielsen, T.H., Marklund, N., Montcriol, A., O'Connell, M.T., Poca, M.A., Sarrafzadeh, A., Shannon, R.J., Skjoth-Rasmussen, J., Smielewski, P., Stover, J.F., Timofeev, I., Vespa, P., Zavala, E. and Ungerstedt, U. (2015). Consensus statement from the 2014 International Microdialysis Forum. Intensive Care Med. 41, 1517-1528.

20. Hutchinson, P.J., O'Connell, M.T., Al-Rawi, P.G., Maskell, L.B., Kett-White, R., Gupta, A.K., Richards, H.K., Hutchinson, D.B., Kirkpatrick, P.J., and Pickard, J.D. (2000). Clinical cerebral microdialysis: a methodological study. J. Neurosurg. 93, 37-43.

21. Assarsson, E., Lundberg, M., Holmquist, G., Bjorkesten, J., Thorsen, S.B., Ekman, D., Eriksson, A., Rennel Dickens, E., Ohlsson, S., Edfeldt, G., Andersson, A.C., Lindstedt, P., Stenvang, J., Gullberg, M., and Fredriksson, S. (2014). Homogenous 96-plex PEA immunoassay exhibiting high sensitivity, specificity, and excellent scalability. PLoS One 9, e95192.

22. Cowpertwait, P.S. and Metcalfe, A.V. (2009). Introductory Time Series with $R$. Vol 1. Springer-Verlag: New York.

23. Helsel, D.R. (2011). Statistics for Censored Environmental Data using Minitab and R. Vol 2. John Wiley \& SonsL Hoboken, NJ.

24. Team, R.C. (2016). R: A Language and Environment for Statistical Computing. R Foundation for Statistical Computing: Vienna, Austria. www.R-project.org/.

25. Csardi, G. and Nepusz, T. (2006). The Igraph Software Package for Complex Network Research. InterJournal Complex Systems: Cambridge, MA.

26. Helmy, A., Carpenter, K.L., Menon, D.K., Pickard, J.D., and Hutchinson, P.J. (2011). The cytokine response to human traumatic brain injury: temporal profiles and evidence for cerebral parenchymal production. J. Cereb. Blood Flow Metab. 31, 658-670.

27. Helmy, A., Guilfoyle, M.R., Carpenter, K.L., Pickard, J.D., Menon, D.K., and Hutchinson, P.J. (2016). Recombinant human interleukin-1 receptor antagonist promotes M1 microglia biased cytokines and chemokines following human traumatic brain injury. J. Cereb. Blood Flow Metab. 36, 1434-1448.

28. Pittaluga, A. (2017). CCL5-glutamate cross-talk in astrocyte-neuron communication in multiple sclerosis. Front. Immunol. 8, 1079.

29. Simats, A., Garcia-Berrocoso, T., Penalba, A., Giralt, D., Llovera, G., Jiang, Y., Ramiro, L., Bustamante, A., Martinez-Saez, E., Canals, F., Wang, X., Liesz, A., Rosell, A., and Montaner, J. (2018). CCL23: a new CC chemokine involved in human brain damage. J. Intern. Med. $283,461-475$.

30. Israelsson, C., Bengtsson, H., Lobell, A., Nilsson, L.N., Kylberg, A., Isaksson, M., Wootz, H., Lannfelt, L., Kullander, K., Hillered, L., and Ebendal, T. (2010). Appearance of Cxcl10-expressing cell clusters is common for traumatic brain injury and neurodegenerative disorders. Eur. J. Neurosci. 31, 852-863.

31. Michlmayr, D., McKimmie, C.S., Pingen, M., Haxton, B., Mansfield, K., Johnson, N., Fooks, A.R., and Graham, G.J. (2014). Defining the chemokine basis for leukocyte recruitment during viral encephalitis. J. Virol. 88, 9553-9567.

32. Israelsson, C., Bengtsson, H., Kylberg, A., Kullander, K., Lewen, A., Hillered, L., and Ebendal, T. (2008). Distinct cellular patterns of upregulated chemokine expression supporting a prominent inflammatory role in traumatic brain injury. J. Neurotrauma 25, 959-974.

33. Israelsson, C., Kylberg, A., Bengtsson, H., Hillered, L., and Ebendal, T. (2014). Interacting chemokine signals regulate dendritic cells in acute brain injury. PLoS One 9, e104754.

34. Maciejewski-Lenoir, D., Chen, S., Feng, L., Maki, R., and Bacon, K.B. (1999). Characterization of fractalkine in rat brain cells: migratory and activation signals for CX3CR-1-expressing microglia. J. Immunol. 163, 1628-1635.

35. Helmy, A., De Simoni, M.G., Guilfoyle, M.R., Carpenter, K.L., and Hutchinson, P.J. (2011). Cytokines and innate inflammation in the pathogenesis of human traumatic brain injury. Prog. Neurobiol. 95, 352-372.

36. Schmidt, O.I., Heyde, C.E., Ertel, W., and Stahel, P.F. (2005). Closed head injury—an inflammatory disease? Brain Res. Brain Res. Rev. 48, 388-399.

37. Shore, P.M., Thomas, N.J., Clark, R.S., Adelson, P.D., Wisniewski, S.R., Janesko, K.L., Bayir, H., Jackson, E.K., and Kochanek, P.M. (2004). Continuous versus intermittent cerebrospinal fluid drainage after severe traumatic brain injury in children: effect on biochemical markers. J. Neurotrauma 21, 1113-1122.

38. Mellergard, P., Aneman, O., Sjogren, F., Saberg, C., and Hillman, J. (2011). Differences in cerebral extracellular response of interleukin1beta, interleukin-6, and interleukin-10 after subarachnoid hemorrhage or severe head trauma in humans. Neurosurgery $68,12-19$.

39. Guilfoyle, M.R., Carpenter, K.L., Helmy, A., Pickard, J.D., Menon, D.K., and Hutchinson, P.J. (2015). Matrix metalloproteinase expression in contusional traumatic brain injury: a paired microdialysis study. J. Neurotrauma 32, 1553-1559.

40. Roberts, D.J., Jenne, C.N., Leger, C., Kramer, A.H., Gallagher, C.N., Todd, S., Parney, I.F., Doig, C.J., Yong, V.W., Kubes, P., and Zygun, D.A. (2013). A prospective evaluation of the temporal matrix metalloproteinase response after severe traumatic brain injury in humans. J. Neurotrauma 30, 1717-1726.

41. Pepe, G., De Maglie, M., Minoli, L., Villa, A., Maggi, A., and Vegeto, E. (2017). Selective proliferative response of microglia to alternative polarization signals. J. Neuroinflammation 14, 236.

42. Hijazi, N., Abu Fanne, R., Abramovitch, R., Yarovoi, S., Higazi, M., Abdeen, S., Basheer, M., Maraga, E., Cines, D.B., and Higazi, A.A (2015). Endogenous plasminogen activators mediate progressive intracerebral hemorrhage after traumatic brain injury in mice. Blood $125,2558-2567$.

43. Hill, L.J., Di Pietro, V., Hazeldine, J., Davies, D., Toman, E., Logan, A., and Belli, A. (2017). Cystatin D (CST5): an ultra-early inflammatory biomarker of traumatic brain injury. Sci. Rep. 7, 5002.

44. Donat, C.K., Scott, G., Gentleman, S.M.. and Sastre, M. (2017) Microglial activation in traumatic brain injury. Front. Aging Neurosci. 9, 208.

45. Morganti, J.M., Riparip, L.K.. and Rosi, S. (2016). Call off the $\operatorname{dog}(\mathrm{ma}): \mathrm{M} 1 / \mathrm{M} 2$ polarization is concurrent following traumatic brain injury. PLoS One 11, e0148001.

46. Shore, P.M., Jackson, E.K., Wisniewski, S.R., Clark, R.S., Adelson, P.D., and Kochanek, P.M. (2004). Vascular endothelial growth factor is increased in cerebrospinal fluid after traumatic brain injury in infants and children. Neurosurgery 54, 605-611.

47. Mellergard, P., Aneman, O., Sjogren, F., Pettersson, P., and Hillman, J. (2008). Changes in extracellular concentrations of some cytokines, chemokines, and neurotrophic factors after insertion of intracerebral microdialysis catheters in neurosurgical patients. Neurosurgery 62, $151-157$.

48. Osborne, B.A. and Minter, L.M. (2007). Notch signalling during peripheral T-cell activation and differentiation. Nat. Rev. Immunol. 7, 64-75.

Address correspondence to:

Fredrik Clausen, $P h D$

Department of Neuroscience

Uppsala University

Uppsala SE 75185

Sweden

E-mail: Fredrik.clausen@neuro.uu.se 